\title{
A comparative study between conventional and non-conventional extraction techniques for the recovery of ergosterol from Agaricus blazei Murrill
}

\author{
Oludemi Taofiqa, ${ }^{\mathrm{a}, \mathrm{e}}$, Rúbia C.G. Corrêa ${ }^{\mathrm{a}, \mathrm{c}, \mathrm{d}}$, Lillian Barros ${ }^{\mathrm{a}, *}$, M.A. Prieto ${ }^{\mathrm{a}, \mathrm{f}}$, Adelar Bracht ${ }^{\mathrm{c}, \mathrm{d}}$, \\ Rosane M. Peralta ${ }^{\mathrm{c}, \mathrm{d}}$, Ana M. González-Paramás ${ }^{\mathrm{e}}$, Maria F. Barreiro ${ }^{\mathrm{a}, \mathrm{b}}$, Isabel C.F.R. Ferreira ${ }^{\mathrm{a}, *}$ \\ ${ }^{a}$ Centro de Investigação de Montanha (CIMO), Instituto Politécnico de Bragança, Campus de Santa Apolónia, 5300-253 Bragança, Portugal \\ ${ }^{\mathrm{b}}$ Laboratory of Separation and Reaction Engineering, Laboratory of Catalysis and Materials (LSRE-LCM), Bragança Polytechnic Institute, 5301-857 Bragança, Portugal \\ ${ }^{\mathrm{c}}$ Department of Biochemistry, State University of Maringá, Paraná, Brazil \\ ${ }^{\mathrm{d}}$ Graduate Program in Food Science, State University of Maringá, Paraná, Brazil

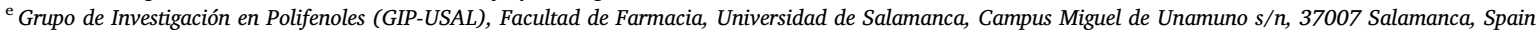 \\ ${ }^{\mathrm{f}}$ Nutrition and Food Science Group, Dept. of Analytical and Food Chemistry, CITACA, CACTI, University of Vigo, Vigo Campus, Vigo, Spain
}

\section{A R T I C L E I N F O}

\section{Keywords:}

Agaricus blazei

Agroindustrial residue, ergosterol

Extraction optimization

Response surface methodology

\begin{abstract}
A B S T R A C T
Response surface methodology was applied to optimize the recovery of ergosterol from an agroindustrial residue of Agaricus blazei Murrill, by comparing conventional (heat-assisted extraction, HAE) and more sustainable nonconventional approaches (ultrasound and microwave-assisted extractions, UAE and MAE, respectively). A circumscribed central composite design was employed to optimize and describe the interactive effects among variables of the HAE, MAE (time and temperature) and UAE systems (time and ultrasound power), and their performances compared with the standard soxhlet extraction system. The optimum conditions were predicted as $150 \mathrm{~min}, 81.6^{\circ} \mathrm{C}$ for $\mathrm{HAE}, 30 \mathrm{~min}, 400 \mathrm{~W}$ for $\mathrm{UAE}$, and $25 \mathrm{~min}, 134.6^{\circ} \mathrm{C}$, for the MAE system. The UAE system was identified as the most appropriate technique to obtain extracts with the highest amount of ergosterol, followed by MAE and HAE. Overall, these results demonstrate the potential of using the fruiting bodies of $A$. blazei as a suitable source to obtain ergosterol-rich extracts, which can be used as an ingredient for various biobased industrial applications.
\end{abstract}

\section{Introduction}

Over the years the importance of sustainable approaches to reduce environmental impacts of by-products from industrial processes have been continually emphasized (Elliot, Shahin, Garcia-garcia, White, \& Needham, 2017). As a consequence of agroindustrial activities, several waste and by products are generated, and often discarded, making their valorization of economic, environmental and scientific interest (Heleno et al., 2016).

The mushroom market has grown steadily during the past decades due to their utilization in the preparation of food, nutraceutical, and cosmeceutical ingredients (Chen et al., 2018; Ferreira et al., 2015; Taofiq, González-Paramás, Martins, Barreiro, \& Ferreira, 2016). Also, mushroom consumption is expected to increase in the coming years, hence the urgent need to find profitable solutions for the re-use of the wastes and by-products of this agroindustry.

Agaricus blazei Murrill (ABM) is a medicinal mushroom, rich in polysaccharides, phenolic acids and ergosterol. In recent years, ABM extracts have become increasingly popular owing to their use in the treatment of many illnesses, as they have proven immunomodulatory, anti-inflammatory, antitumor, antioxidant and antiviral properties (Lima, Gris, \& Karnikowski, 2016; Zhai, Wang, \& Han, 2015). However, $\mathrm{ABM}$ is marketed and consumed in ways that have not been scientifically confirmed as delivering the desired effect (Firenzuoli, Gori, \& Lombardo, 2008). Also, ABM fruiting bodies are commonly consumed as teas and beverages, thus generating large quantities of residual materials that can find use as a source of high added value bioactive compounds for several bio-based applications (Firenzuoli et al., 2008). Similarly, an expressive volume of $A$. blazei basidiocarps do not fit into the commercial standards, being predominantly discarded by farmers and processing industries. These bio-residues could be further explored in the recovery of high value molecules and thus gain added-value (Corrêa et al., 2018).

Among the bioactive compounds present in $\mathrm{ABM}$, there is an increasing interest on ergosterol, because of its well-known anti-inflammatory (Taofiq, Martins, Barreiro, \& Ferreira, 2016), anti-

\footnotetext{
* Corresponding authors.

E-mail addresses: lillian@ipb.pt (L. Barros), iferreira@ipb.pt (I.C.F.R. Ferreira).
} 
tyrosinase (Taofiq, González-Paramás, et al., 2016), and anti-cancer (Kang et al., 2015) activities, together with their use in new drug formulations with antibiotics (Tintino et al., 2017). Consumption of functional foods with hypocholesterolemic properties is reported to be an effective strategy to reduce the risks of cardiovascular diseases, with the most widely used bio-based ingredients in commercial products being plant phytosterols and $\beta$-glucans (Gil-Ramírez et al., 2013). In this context, ergosterol, which is structurally similar to phytosterols, can be utilized as a natural ingredient to reduce cholesterol levels (Corrêa, Peralta, Bracht, \& Ferreira, 2017). A recent cytotoxic advancement was also made with agarol, an ergosterol derivative obtained from $\mathrm{ABM}$, found to induce caspase-independent apoptosis in human cancer cells, making it a promising ingredient for novel anticancer formulations (Shimizu et al., 2016). On account of these pharmaceutical advancements, more studies reporting the extraction of ergosterol from mushrooms is important to be conducted.

An increasing reliance on the use of natural based extracts in the industrialized society has been established for years, hence pushing the need to find suitable extraction methods. Conventional heat assisted extraction methods (HAE, or maceration), although employed at largescale production, often use organic solvents and need several additional steps to recover the extract, are also known to be high-energy and time consuming processes (Wang et al., 2013; Wang, Jung, Tomasino, \& Zhao, 2016; Zhu et al., 2016). Alternative extraction processes such as the ones based on ultrasound (UAE) and microwave (MAE) energy sources, and supercritical fluid assisted extraction have been established as efficient and/or economically attractive industrial processes (shorter extraction time, low energy consumption and low solvent consumption) (Roriz, Barros, Prieto, Morales, \& Ferreira, 2017; Zhu et al., 2016).

Both UAE and MAE are known to accelerate extraction of various biomolecules and their effectiveness depends on the selected operating conditions. This is evident in some studies conducted by Heleno, Prieto, et al. (2016) and Heleno, Diz, et al. (2016), where factors such as solvent type, time and temperature, were reported to influence the extraction of ergosterol from mushrooms using non-conventional procedures, such as microwave assisted extraction (MAE) and ultrasound assisted extraction (UAE). When studying a productive process, such as extraction, the influence of each variable can be globally assessed by applying mathematical modeling such as the response surface methodology (RSM), that allows to optimize the interactions between experimental variables and, simultaneously, to predict the most efficient conditions (Albuquerque et al., 2016; Thirugnanasambandham \& Sivakumar, 2017).

To fully harness the beneficial effects of the ergosterol-rich extracts obtained from ABM, studies on the extraction procedure need to be conducted. In a general way, these studies aim to maximize the recovery of bioactive molecules from natural sources, identify the most appropriate extraction techniques and their optimal operational conditions (Jiménez et al., 2018). In fact, the efficiency is strongly affected by the discrepancies observed among different matrices (Montesano et al., 2008), demanding dedicated studies for each particular case.

The aim of the present work is to study the obtainment of ergosterol-rich extracts from A. blazei bioresidues using different techniques, from conventional HAE, to non-conventional MAE and UAE, and their comparison with a standard Soxhlet (SE) system. The combined variable effects such as temperature, time and power, depending on the applied process, were analyzed by RSM aiming to find the optimized conditions for each technique and discuss the most suitable one for the envisaged purpose. To the author's best knowledge, there are no reports available comparing conventional techniques and novel technologies for ergosterol extraction from the chosen ABM mycological matrix.

\section{Material and methods}

\subsection{Mushroom samples}

The used fruiting bodies (basidiocarps) of $A$. blazei were donated by a local producer of Maringá, Paraná, Brazil, and were harvested in Spring 2016. ABM fruiting bodies were classified into two groups (Soares et al., 2009): (1) immature basidiocarps, those that had still a closed pile corresponding to the ones with the high market value; and (2) mature basidiocarps, those totally open, and therefore considered off-market specimens (by-product). In the present work only the fruiting bodies of group 2 were used, that is, agroindustrial residues of ABM. The samples were dried in a circulation oven at $40^{\circ} \mathrm{C}$ and milled to a fine powder ( $\sim 40$ mesh), then mixed to constitute homogenized samples. Finally, the samples were vacuum packed and stored at room temperature.

\subsection{Standards and reagents}

Methanol and acetonitrile were of HPLC grade acquired from Fisher Scientific (Lisbon, Portugal). The sterol standards (ergosterol and cholecalciferol) were purchased from Sigma (St. Louis, MO, USA). Water was treated in a Milli-Q water purification system (TGI Pure Water Systems, Greenville, SC, USA). All other chemicals and solvents including ethanol (chosen as the extraction solvent based on the work), were of analytical grade and purchased from common suppliers.

\subsection{Ergosterol extraction by standard method and conventional system}

\subsubsection{Extraction by Soxhlet (SE)}

The dry mushroom samples $(3 \mathrm{~g})$ were extracted with $100 \mathrm{~mL}$ of ethanol $(30 \mathrm{~g} / \mathrm{L})$ in a Soxhlet apparatus $\left(\sim 75^{\circ} \mathrm{C}\right)$. To compare the efficiency of the extraction system, the number of cycles in the SE was taken into consideration and up to 8 cycles were analyzed. After the desired number of cycles were achieved, the solvent was evaporated under reduced pressure (rotary evaporator Büchi R-210, Flawil, Switzerland) to obtain a dried ethanolic extracts. These results were recently reported by Corrêa et al. (2018).

\subsubsection{Heat-assisted extraction (HAE)}

The powdered mushroom samples $(600 \mathrm{mg})$ were placed in a closed flask with $20 \mathrm{~mL}$ of ethanol maintaining the solid/liquid ratio $(S / L)$ at $30 \mathrm{~g} / \mathrm{L}$. The beaker was placed in a thermostatic water bath and kept under continuous electro-magnetic stirring using a CIMAREC i Magnetic Stirrer at a fixed stirring rate $(500 \mathrm{rpm}$, Thermo Scientific, San Jose, CA, USA). Extractions were conducted using different times $(t)$ and temperature $(T)$ as pre-established by the RSM design: $t$ (10 to $150 \mathrm{~min})$ and $T\left(30\right.$ to $\left.90^{\circ} \mathrm{C}\right)$.

\subsection{Non-conventional extraction techniques}

\subsubsection{Microwave-assisted extraction (MAE)}

The MAE process was performed using a Biotage Initiator Microwave (Biotage ${ }^{\circledast}$ Initiator + , Uppsala, Sweden) equipped with closed vessels. The powdered mushroom samples $(300 \mathrm{mg})$ were extracted with $10 \mathrm{~mL}$ of ethanol maintaining the $S / L$ at $30 \mathrm{~g} / \mathrm{L}$. The variables and ranges tested were: $t$ ( 2 to $25 \mathrm{~min}$ ) and $T$ (60 to $150^{\circ} \mathrm{C}$ ). During processing, the fixed hold-time and cooling options were "off", samples were stirred at $600 \mathrm{rpm}$ using a magnetic stirring bar, and the power variable was set at $400 \mathrm{~W}$ Pinela, et al. (2016a, b). 


\subsubsection{Ultrasound-assisted extraction (UAE)}

The UAE was carried out using an ultrasonic probe device (QSonica sonicators, model CL-334, Newtown, CT, USA). The dried mushroom powder ( $3 \mathrm{~g}$ ) was extracted with $100 \mathrm{~mL}$ of ethanol maintaining the $S / L$ at $30 \mathrm{~g} / \mathrm{L}$, using different $t$ ( 5 to $30 \mathrm{~min}$ ) and ultrasound power (P, 100 to $400 \mathrm{~W}$ ), while the $T$ was maintained in the range $30-35^{\circ} \mathrm{C}$ using an ice bath.

\subsection{Yield determination and ergosterol quantification}

After the applied extraction procedure, the samples were filtered, and the resulting ethanolic extract was evaporated to dryness at $35^{\circ} \mathrm{C}$ (rotary evaporator Büchi R-210, Flawil, Switzerland). To calculate the yield, a sample of $5 \mathrm{~mL}$ of the obtained extract was dried at $105{ }^{\circ} \mathrm{C}$ to determine the corresponding dry weight.

To quantify the ergosterol, the obtained dry extracts were re-dissolved in ethanol at a final concentration of $30 \mathrm{mg} / \mathrm{mL}$, then filtered through a $0.22 \mu \mathrm{m}$ nylon disposable filter, and analyzed by HPLC-UV (Knauer, Smartline system 1000, Berlin, Germany) following a procedure previously described by Barreira, Oliveira, and Ferreira (2013). The used column was an Inertsil 100A ODS-3 reversed-phase $(5 \mu \mathrm{m}$, $4.6 \times 150 \mathrm{~mm}$, BGB Analytik AG, Boeckten, Switzerland) operating at $35^{\circ} \mathrm{C}$ (7971R Grace oven). The mobile phase was acetonitrile/methanol $(70: 30, v / v)$ at a flow rate of $1 \mathrm{~mL} / \mathrm{min}$ was used, and detection was performed at $280 \mathrm{~nm}$. The calibration curve was obtained from a commercial ergosterol standard, and by using cholecalciferol as the internal standard. Clarity 2.4 Software (DataApex) was employed for data analysis.

\subsection{Response surface methodology}

The RSM family designs are useful for modeling and analyze problems in which a response of interest is influenced by several variables. The RSM was applied to optimize the HAE, MAE, and UAE techniques with the purpose of finding the most favorable conditions conducting to efficiencies similar to those obtained with the SE system.

\subsubsection{Responses format values to present the results}

The results were expressed according to three response $(Y)$ format values: $Y_{1}$, the $\%$ of extracted material (R), which was used to evaluate the total extraction yield; $Y_{2}$, in mg of ergosterol per $\mathrm{g}$ of extract residue (mg E/g R), which was used to evaluate the ergosterol purity in the extract; and $Y_{3}$, in mg of ergosterol per $100 \mathrm{~g}$ of dry mushroom A. blazei (mg E/100 g M dw), which was used to analyze the extraction yield expressed in ergosterol.

\subsubsection{Preliminary tests to assess the effect of variables and collateral factors on ergosterol extraction}

Initial tests were carried out to screen the appropriate variables to determine their experimental domain for an appropriate RSM design. Independent variables, which include $t$ and $T$ for HAE and MAE, and $t$ and $P$ for UAE, were preliminarily tested.

\subsubsection{Experimental design}

Trials were conducted based on one-at-the-time analysis of each one of the variables and each one of the selected techniques. The variables that caused significant changes, and the relevant ranges of action, were selected for each one of the studied extraction methodologies (Table A1, Supplementary material). The variables were coded according to the needs of the experimental design. For each technique, the combined effect of the two relevant variables, was studied using a circumscribed central composite design (CCCD) using five levels for each one with 16 response combinations (three replicates per condition). Experimental runs were randomized, to minimize the effects of unexpected variability in the observed responses. Previous studies carried out on recovery of ergosterol from mushrooms were used to determine the experimental domain (Barreira et al., 2013; Heleno, Diz, et al., 2016a; Heleno, Prieto, et al., 2016b).

\subsubsection{Mathematical model}

Response surface models were fitted by means of least-squares calculation using the following second order polynomial equation,

$Y=b_{0}+\sum_{i=1}^{n} b_{i} X_{i}+\sum_{\substack{i=1 \\ j>i}}^{n-1} \sum_{j=2}^{n} b_{i j} X_{i} X_{j}+\sum_{i=1}^{n} b_{i i} X_{i}^{2}$

where $Y$ is the dependent variable (response variable) to be modeled, $X_{i}$ and $X_{j}$ define the defined independent variables, $b_{o}$ is the constant coefficient, $b_{i}$ is the coefficient of linear effects, $b_{i j}$ is the coefficient of interaction effects, $b_{i i}$ the coefficients of quadratic effects and $\mathrm{n}$ is the number of variables. The variables $X_{1}$ and $X_{2}$ were $t$ and $T$ or P (for HAE and MAE $t$ and $T$ were used, whereas for UAE $t$ and P were chosen). Regarding the responses, three different response formats were used as the dependent variables: $Y_{1}$, response format value in $\%$, to analyze the total extraction yield; $Y_{2}$, the response format value in $\mathrm{mg} / \mathrm{g}$ of extract to analyze the ergosterol purity in the extract and $Y_{3}$ the response format value in $\mathrm{mg} / 100 \mathrm{~g} \mathrm{M} \mathrm{dw}$ to analyze the extraction yield in ergosterol.

\subsubsection{Procedure to optimize the variables to a maximum response}

A simplex method was used to optimize the predictive model by solving nonlinear problems in order to maximize the responses $\left(Y_{1}, Y_{2}\right.$ and $Y_{3}$ individually or globally (Vieira et al., 2017). Certain limitations were imposed (i.e. $t$ cannot be lower than 0 ) to avoid variables with unnatural and unrealistic physical conditions.

\subsection{Dose-response analysis of the solid-to-liquid ratio}

Once the optimal conditions ( $X_{1}$ and $X_{2}$ ) were found by RSM, the following natural optimization step was to describe the pattern of the solid-to-liquid ratio $\left(S / L\right.$ or $X_{3}$, expressed in $\mathrm{g} / \mathrm{L}$ ) aiming at achieve a more productive process for industrial applications. To depict the response effect as function of the the $S / L$ variation, the Weibull (W) equation (Prieto, Curran, Gowen, \& Vázquez, 2015) for increasing ( $\uparrow$ ) and decreasing $(\downarrow)$ responses was used with some parametric modifications to fit the searched purposes:

$\uparrow W\left(X_{4}\right)=K \exp \left[\ln (1-n / 100)\left(\frac{X_{4}}{m_{n}}\right)^{a}\right] \quad$ or $\quad \downarrow W\left(X_{4}\right)=K-K \exp \left[\ln (1-n / 100)\left(\frac{X_{4}}{m_{n}}\right)^{a}\right]$

where $K$ is the maximum extraction value (response criteria units, i.e., if $Y_{2}$ units would be $\mathrm{mg} / \mathrm{g} \mathrm{R}$ ), $a$ is a shape parameter related to the maximum slope of the response, $\mathrm{n}$ is any desired level between 0 and $100 \%$ of the response $\left(Y_{1}, Y_{2}\right.$ and $\left.Y_{3}\right)$ that would be achieved, and $m_{n}$ would be the $S / L$ value $\left(X_{3}\right)$ for such a response level of n selected $\left(m_{10}\right.$, $m_{25}, m_{75}, m_{95}$, etc.). For example, if $99 \%$ was select for the $\mathrm{n}$ value, the $m_{n}$ parameter will display de needed $S / L$ needed to achieve $99 \%$ of the assessed response $\left(m_{99 \%}\right)$. When the response shows increasing patterns $(\uparrow)$, the Weibull equation that will be used to describe the response will present a $m_{n}$ parameter with $\mathrm{n}=99 \%$. When the response shows decreasing patterns $(\downarrow)$, a $m_{n}$ parameter with $n=50 \%$ will be used. These different levels of the response as a function of the increasing or decreasing patterns of the response are logical relations of the intrinsic solutions for industrial purposes. When the response increases, it seems to be logical to know the maximum $S / L$ value needed to achieve $99 \%$ of the assessed response $\left(m_{99 \%}\right)$, as it is the case for $Y_{2}$ and $Y_{3}$ responses. However, when the response decreases, the value of $m_{99 \%}$ will be approximately zero. Therefore, it seems to be logical to search for values that do not decrease our response more than the half of the maximum value (such as $m_{50 \%}$ ), as it is the case for $Y_{1}$ response. If other $m_{n}$ are required, Eq. (2) can be modified to produce any other desirable result. However, the selected parameter values for $K$ and $m_{n}$ provide key 
information related to the pattern of the response to assess the $S / L$ trend.

\subsection{Numerical methods and statistical analysis}

Fitting procedures, coefficient estimates and statistical calculations were performed as previously described by Pinela, et al. (2016a, b). In brief, a) the coefficient measurement was carried out using the nonlinear least-square (quasi-Newton) method provided by the macro "Solver" in Microsoft Excel, which allows minimizing the sum of the quadratic differences between the observed and model-predicted values; b) the coefficient significance was evaluated using the 'SolverAid' to determine the parametric confidence intervals. The non-statistically significant terms (p-value $>.05$ ) were dropped to simplify the model; and c) the model reliability was verified using the following statistical assessment criteria: i) the Fisher $F$-test $(\alpha=0.05)$ was used to determine whether the constructed models were adequate to describe the observed data; ii) the 'SolverStat' macro was used for the assessment of parameter and model prediction uncertainties; iii) the $R^{2}$ and $R_{\text {adj }}^{2}$ were interpreted as the proportion of variability, of the dependent variable explained by the model; and iv) bias and accuracy factors of all equations were calculated to evaluate the fittings of the experimental data, such as the mean squared error (MSE), the root mean square of the errors (RMSE), the mean absolute percentage error (MAPE) and the Durbin-Watson coefficient (DW).

\section{Results and discussion}

\subsection{Ergosterol extraction by standard Soxhlet method}

In the present work, $\mathrm{ABM}$ fruiting bodies were submitted to $\mathrm{SE}$ (standard technique) to obtain reference values to compare with the chosen conventional (HAE) and non-conventional extraction techniques (MAE and UAE). The SE was carried out using eight Soxhlet cycles each one lasting about $30-40 \mathrm{~min}$. From the obtained results, the highest ergosterol yield was achieved at the 5 th cycle, which corresponds to $4 \mathrm{~h}$ of sample continuous contact with the hot solvent. The responses were as follows: extraction yield of $12 \%\left(Y_{1}\right)$, ergosterol purity of $4.80 \mathrm{mg} \mathrm{E} / \mathrm{g} \mathrm{R}\left(Y_{2}\right)$ and yield in ergosterol of $58.53 \mathrm{mg} \mathrm{E} / 100 \mathrm{~g} \mathrm{dw}\left(Y_{3}\right)$. These results were previously reported by Corrêa et al. (2018). They were used in the present work to compare with those obtained with HAE, MAE and UAE techniques to identify efficient alternatives to SE for ergosterol recovery.

\subsection{Efficiency of ergosterol extraction by conventional and non- conventional technologies optimized by RSM}

RSM is a proficient tool to evaluate the effects of numerous variables and their interactions on one or more responses. The CCCD is a popular form of RSM and has been applied by a number of researchers for optimization of various food processing methods (Bezerra et al., 2008). Fig. 1 shows a comprehensive summary of the different steps carried out in the optimization of ergosterol extraction from the fruiting bodies (basidiocarps) of A. blazei. RSM was applied to study the level of significance of each independent variable, for each one of the carried extraction methods, on their respective responses to be able to fully describe the interactive effects among the numerous factors.

\subsubsection{Theoretical mathematical models derived from the RSM analysis}

In the present study, a total of 16 experimental runs were needed to optimize the extraction and produce the parametric values for model development in HAE, UAE and MAE with responses defined as $Y_{1}, Y_{2}$ and $Y_{3}$. Table A1 (Supplementary material) shows the experimental conditions; the responses according to the statistical CCCD experimental design are presented in Table 1 , for each one of the computed extraction techniques. By fitting the second-order polynomial model of
Eq. (1) to the obtained responses, using nonlinear least-squares estimations, the parametric values are obtained and presented in Table 2 Part A.

The coefficients showing confidence interval values $(\alpha=0.05)$ higher than the parameter value, were consider as non-significant ( $n s)$, and were not accounted in the model development. In statistical terms, the $n s$ parameters of the RSM approaches do not improve the reached solution of the models, but increase the uncertainties of all significant parameters and, in addition, the $n s$ parameters distort the predicted solutions in untested conditions. This has already been described in the literature (Ranic et al., 2014), and suggested as a mandatory step to avoid irregularities in the mathematical analysis, such as response overfitting and inaccurate predictions of the results of untested operating conditions. Therefore, based in the results presented in Table 2A, the final resulting models for each one of the assessed extraction techniques were the following:

For the response format $Y_{1}$ (yield of the extracted $\mathrm{R}$ material, \%):

for HAE: $Y_{H A E}^{Y_{1}}=9.90+0.86 t+5.23 T+0.42 t T$

for UAE: $Y_{U A E}^{Y_{1}}=1.49+0.09 t-0.26 P^{2}+0.10 t P$

for MAE: $Y_{M A E}^{Y_{1}}=13.40+1.26 t+5.12 T-1.50 T^{2}$

For te response format $Y_{2}(\mathrm{mg} \mathrm{E} / \mathrm{g} \mathrm{R})$ :

$$
\begin{aligned}
& \text { for HAE: } Y_{H A E}^{Y_{2}}=6.47+0.71 t+2.96 T-0.36 t^{2}-0.24 T^{2}+0.29 t T \\
& \text { forUAE: } Y_{U A E}^{Y_{2}}=1.80+0.03 t+0.29 P-0.21 P^{2}-0.03 t P \\
& \text { for MAE: } Y_{M A E}^{Y_{2}}=13.15+1.97 t+5.41 T-1.15 t^{2}-1.53 T^{2}+1.63 t T
\end{aligned}
$$

For the response format $Y_{3}(\mathrm{mg} \mathrm{E} / 100 \mathrm{~g} \mathrm{M} \mathrm{dw})$ :

$$
\begin{aligned}
& \text { for HAE: } Y_{H A E}^{Y_{3}}=18.57+5.18 T-0.46 t^{2}-1.21 T^{2}-0.19 t T \\
& \text { for UAE: } Y_{U A E}^{Y_{3}}=1.09+0.10 t-0.12 P-0.09 t P \\
& \text { for MAE: } Y_{M A E}^{Y_{3}}=19.83+2.50 t+4.92 T-1.69 T^{2}-0.80 t T
\end{aligned}
$$

The variable models of Eqs. (3)-(11) derived from Eq. (1), where $X_{1}$ $(t, \min )$ and $X_{2}\left(T,{ }^{\circ} \mathrm{C}\right.$ or $\left.\mathrm{P}, \mathrm{W}\right) ; Y$ is the response, with the sub-indices indicating the applied technique and the super-indices the three used response criteria ( $Y_{1}$ in \%, $Y_{2}$ in $\mathrm{mg} \mathrm{E} / \mathrm{g} \mathrm{R}$ and $Y_{3}$ in $\left.\mathrm{mg} \mathrm{E} / 100 \mathrm{~g} \mathrm{M} \mathrm{dw}\right)$. The parametric information presented in Table 2A or Eqs. (3)-(11), provides a complete summary of the effects caused by each one of the variables defined for each extraction system. These equations translate the response patterns, showing a relatively high complexity (higher than 5 parameters) of the possible sceneries for the $Y_{1}$ and $Y_{2}$ value formats and relatively simple solutions for the $Y_{3}$ response value format $(<4$ parameters).

Since the experimental plan is based on coded values of the variables, the obtained model coefficients are empirical and cannot be associated with physical or chemical parameters. However, their numerical values can be used for direct comparisons. In fact, the higher the absolute value of the coefficients is, the more important will be the weight of the corresponding variables. Correspondingly, when a factor has a positive effect, the response increases as the value of the involved variable increase, and when the factor has a negative effect, the response decreases.

\subsubsection{Graphical illustrations and general analysis of the results}

(Figs. 2-4) show the fitting analysis, graphical descriptions of the responses as a function of each defined variable, statistical analysis and optimal conditions that maximize the assessed response format value $\left(Y_{1}, Y_{2}\right.$ and $\left.Y_{3}\right)$ of each variable for the HAE, UAE and MAE techniques. In each of these figures (Figs. 2-4), the illustration is divided in four sections: 


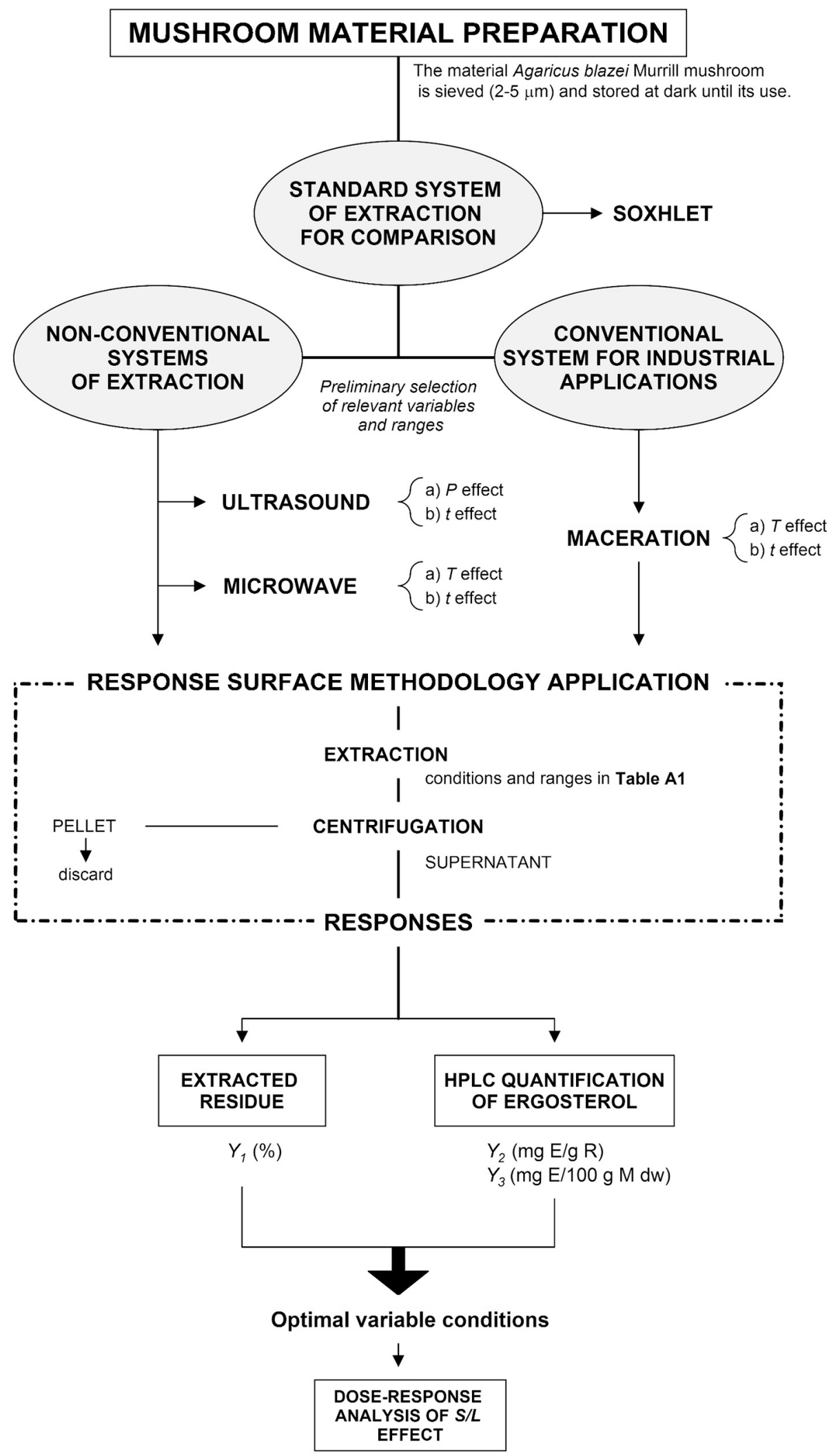

Fig. 1. Diagram of the different steps carried out for optimizing the conditions that maximize the extraction responses $\left(Y_{2}\right.$ in $\mathrm{mg} \mathrm{E} / \mathrm{g} \mathrm{R}$ and $Y_{3}$ in $\mathrm{mg} \mathrm{E} / 100 \mathrm{~g} \mathrm{M}$ dw) of the ergosterol compound and the total extracted residue $\left(Y_{1}\right.$ in \%). 
Table 1

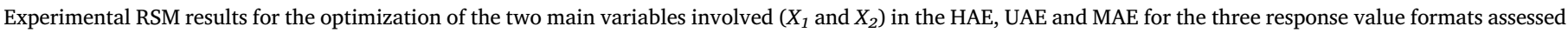

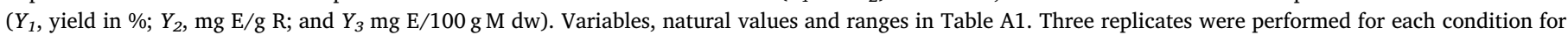
each technique.

\begin{tabular}{|c|c|c|c|c|c|c|c|c|c|c|}
\hline \multicolumn{2}{|c|}{ Coded values } & \multicolumn{9}{|c|}{ Experimental responses } \\
\hline & & \multicolumn{3}{|c|}{ Heat assisted extraction (hae) } & \multicolumn{3}{|c|}{ Ultrasound assisted extraction (uae) } & \multicolumn{3}{|c|}{ Microwave asssisted extraction (mae) } \\
\hline$X_{1}$ & $X_{2}$ & $Y_{1}$ & $Y_{2}$ & $Y_{3}$ & $Y_{1}$ & $Y_{2}$ & $Y_{3}$ & $Y_{1}$ & $Y_{2}$ & $Y_{3}$ \\
\hline-1 & -1 & 3.33 & 1.14 & 3.80 & 1.55 & 1.21 & 1.88 & 13.18 & 0.48 & 6.33 \\
\hline-1 & 1 & 15.32 & 1.05 & 16.15 & 8.08 & 2.11 & 17.02 & 22.70 & 0.95 & 21.51 \\
\hline 1 & -1 & 4.25 & 1.66 & 7.07 & 1.87 & 1.23 & 2.31 & 12.05 & 1.52 & 18.39 \\
\hline 1 & 1 & 19.20 & 0.67 & 12.87 & 9.24 & 2.13 & 19.74 & 18.59 & 0.70 & 12.99 \\
\hline-1.41 & 0 & 6.70 & 1.06 & 7.20 & 4.18 & 1.93 & 8.06 & 15.90 & 1.03 & 16.32 \\
\hline 1.41 & 0 & 10.63 & 1.65 & 17.54 & 8.81 & 1.60 & 14.10 & 18.58 & 1.34 & 24.93 \\
\hline 0 & -1.41 & 3.51 & 0.50 & 1.75 & 1.70 & 1.14 & 1.94 & 7.49 & 1.15 & 8.60 \\
\hline 0 & 1.41 & 14.30 & 1.39 & 19.91 & 11.77 & 1.59 & 18.72 & 24.30 & 1.07 & 26.14 \\
\hline-1.41 & -1.41 & 3.34 & 0.79 & 2.66 & 1.89 & 0.71 & 2.74 & 6.91 & 0.98 & 6.81 \\
\hline-1.41 & 1.41 & 16.63 & 0.91 & 15.21 & 7.43 & 1.64 & 5.85 & 22.32 & 0.90 & 20.04 \\
\hline 1.41 & -1.41 & 4.40 & 1.42 & 6.23 & 1.81 & 1.20 & 2.18 & 8.85 & 1.59 & 14.11 \\
\hline 1.41 & 1.41 & 20.45 & 1.01 & 20.56 & 9.82 & 2.08 & 20.43 & 23.84 & 0.99 & 23.78 \\
\hline 0 & 0 & 8.91 & 1.84 & 16.43 & 6.63 & 1.64 & 10.90 & 19.03 & 1.15 & 21.91 \\
\hline 0 & 0 & 9.15 & 1.67 & 15.27 & 6.67 & 1.84 & 12.28 & 18.73 & 1.02 & 19.03 \\
\hline 0 & 0 & 9.63 & 1.54 & 14.92 & 6.16 & 2.54 & 15.63 & 18.76 & 1.10 & 20.62 \\
\hline 0 & 0 & 9.70 & 1.49 & 14.45 & 6.29 & 2.20 & 13.82 & 19.33 & 1.03 & 19.97 \\
\hline
\end{tabular}

- Part A shows the surface plots in 3D response surface predicted with the second order polynomial Eq. (1) as a function of each one of the involved variables.

- Part B shows the 2D contour plots of the simulations achieved with the models of Eqs. (3)-(11) after fitting the experimental results to Eq. (1).

- Part C shows an illustration of the statistical robustness of the performed mathematical analysis. Two basic graphical criteria were used: the ability to simulate the changes of the response using the correlation between experimental and predicted values and the residual distribution as a function of each of the variables.

- Part D shows the summarized individual 2D responses as a function of the defined variables for the HAE, UAE and MAE extraction systems to guide the selection of the most favorable conditions. The line represents the variable response pattern when the others are located at the optimal values. The dots $(\odot)$ presented alongside the line highlight the location of the optimal value.

Observing the response surface plots for the extraction yield in the HAE system in Fig. 2, it is possible to verify that the amount of extracted material increases up to a maximum value as $t$ and $T$ increase. On the other hand, in the UAE system the amount of extracted material increases to an optimum value and then starts to decrease as a function of $t$ and P. In the MAE technique, a higher $T$ favors a faster diffusion, thus achieving a higher content in $Y_{1}$ due to an increase in the solubility and diffusion coefficient from the solid to the liquid matrix. Despite this positive effect on the extraction yield, increasing $T$ may also affect the stability of the compound of interest. Hence, a combination of lower $t$ and moderate $T$ resulted in a better extraction yield. Observing the predicted surfaces for $Y_{2}$ response format value (mg E/g R) in.

Fig. 3, it is possible to draw the following conclusions: in MAE, a negative interactive effect between variables was observed (positive for $t$ and negative for T), which indicates that higher $t$ might be beneficial to improve exudation of active constituents from the ruptured cell walls, but prolonged exposure may cause compound deterioration, thus reducing the ergosterol purity in the extract. In the UAE system, the variable $\mathrm{P}$ was found to have a positive effect on $Y_{2}$. The 2D response contour plot of.

Fig. 3 (Part B), shows mutual interactions between the variables, whereas the circular contour plot reveals less interaction between the corresponding variables, and the elliptical contour plot shows the most significant interactions between the variables. The 2D plot for the UAE technique shows the most significant interactions, meaning that a moderate value of $t$, and a higher $\mathrm{P}$ value generated the highest yield in ergosterol (mg E/g R). Observing Fig. 4 and comparing the results among all the techniques, it allows to conclude that MAE gave significantly higher values at a shorter $t$. The results with the UAE technique indicates that $Y_{3}$ increased as a function of $\mathrm{P}$ and $t$ increase, while an opposite effect was observed for HAE.

\subsubsection{Statistical and experimental verification of predictive models}

To assess the competence of the obtained models of Eqs. (3)-(11), several statistical tests were used, and the results are presented in Table 2B. In general, for all the developed models, the statistical tests merge into the same conclusions: the models are practical and can be applied effectively in subsequent prediction stages. In fact, the most common statistical criteria presented in Table 2B, coefficients $R^{2}$ and $R_{a d j}^{2}$, in all cases, displayed values higher than 0.8 , which indicates a good agreement between the experimental and predicted values. The distribution of the experimental and predicted values can be visualized in part C of Figs. $2-4$. Indeed, it suggests that $>80 \%$ of variability was successfully explained by the model, thus indicating the suitability of the model and a high level of correlation between the observed and predicted values. For all extraction methodologies, all experimental points were found to be close to the line of perfect fit, suggesting an accurate correlation between the predicted and experimental values, what further confirms the suitability of the employed model. Additionally, the residuals distribution presented in Part C of Figs. 2-4 was in all cases arbitrarily distributed around zero, and no group of values or autocorrelations were observed. This implies that the variation of the experimental results can be explained by the independent processing variables by using the specific parametric values presented in Table $2 \mathrm{~A}$, which validates the models of Eqs. (3) - (11), and allows the determination of the optimal conditions that will maximize the responses.

\subsubsection{Numerical optimal conditions that maximize the extraction and experimental verification of predictive models}

By applying a simplex method to solve nonlinear problems, the optimum individual condition maximizing the recovery of ergosterol were determined for the three possible response format values. In addition, the global optimum conditions can also be determined. Both individual and global optimal conditions are presented in Table 3. The best results of the found optimal individual values, for each of the responses, are as follows: 


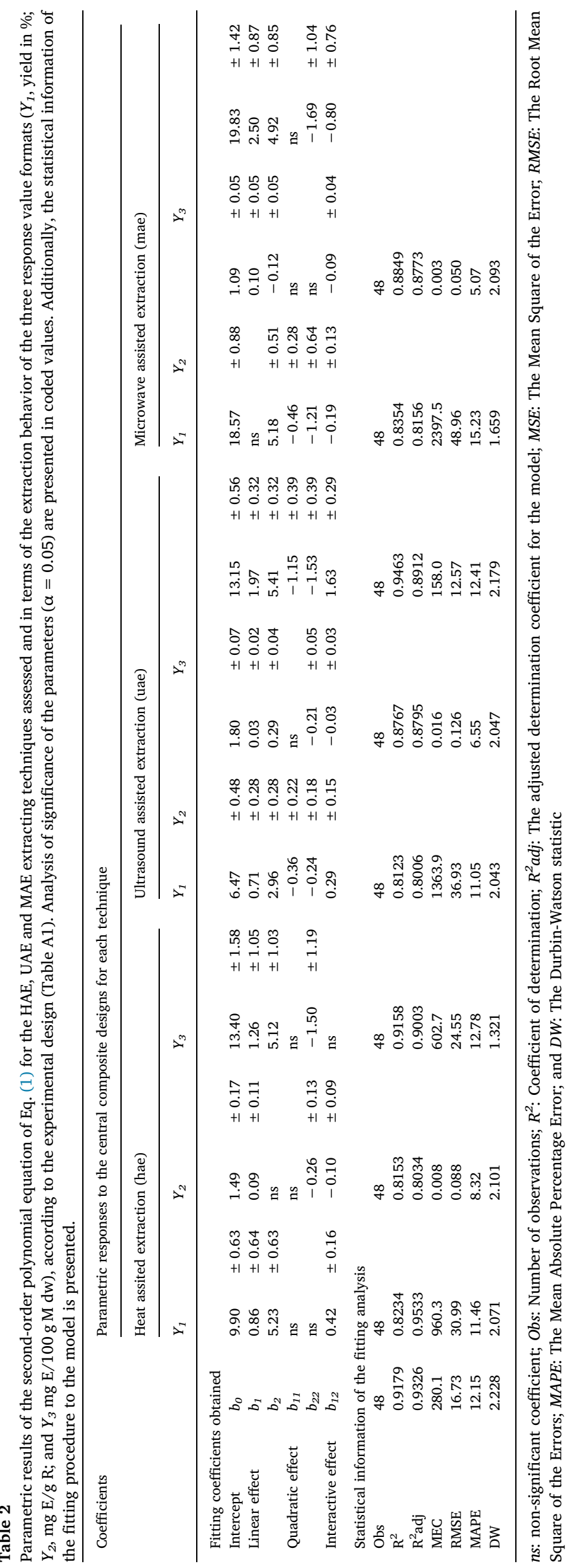




\section{A: JOIN ACTION (3D)}
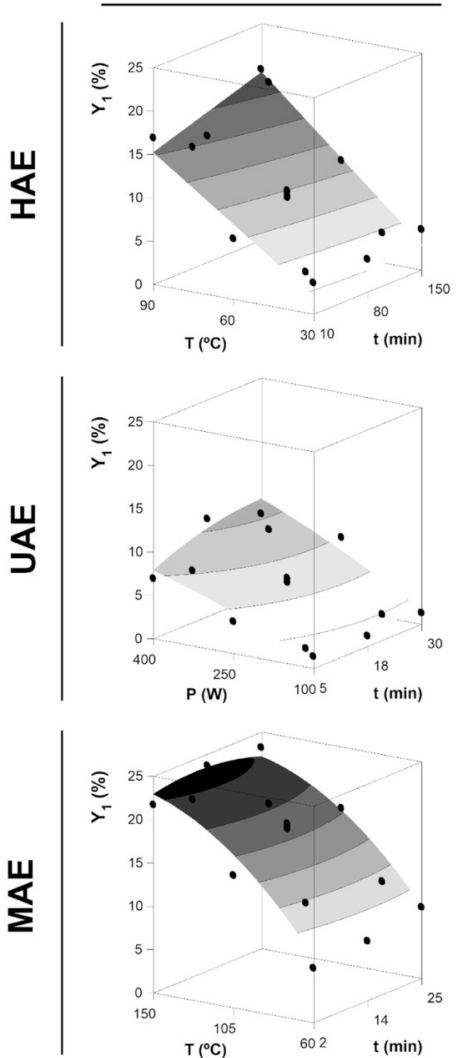
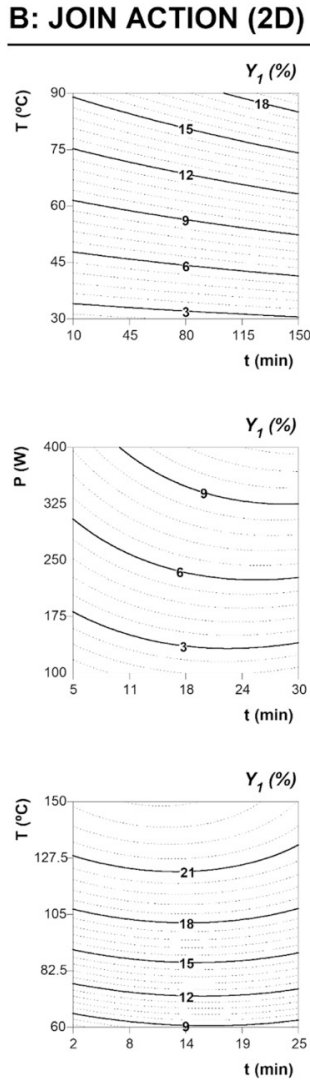

\section{C: STATISTICAL ANALYSIS}
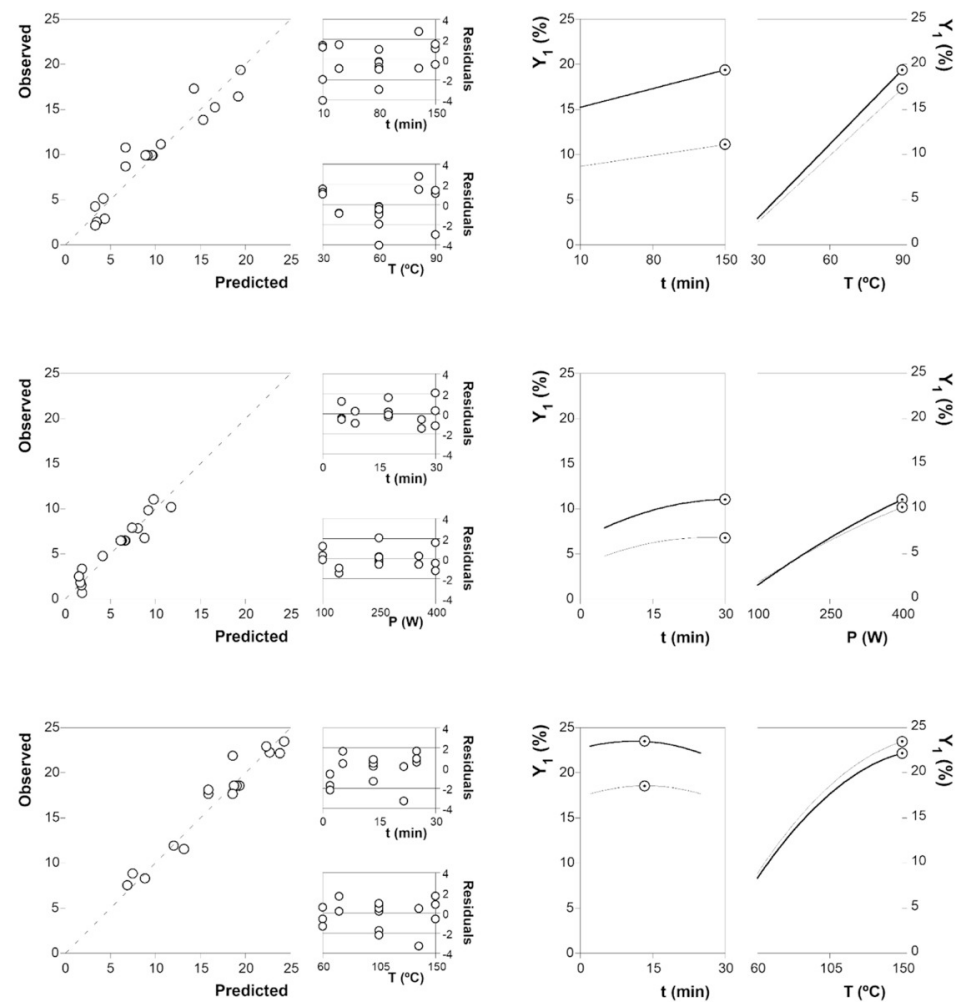

\section{D: OPTIMAL VALUES}
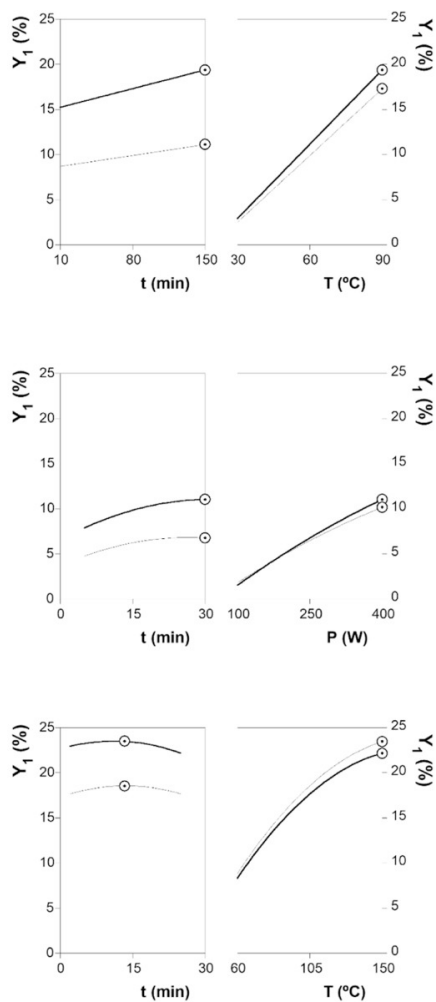

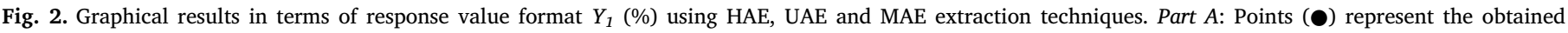

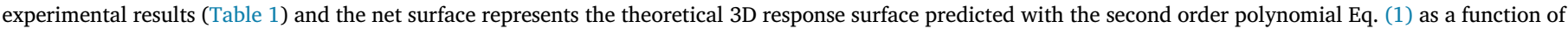

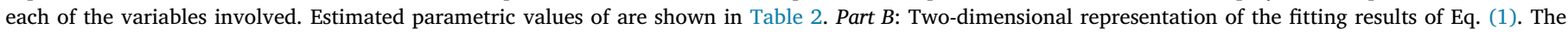

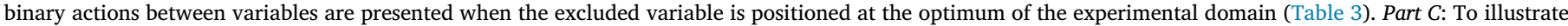

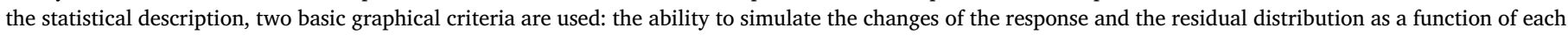
of the variables. Part $D$ : The dots $(\odot)$ presented alongside each line highlight the location of the optimum value. Lines are generated by Eq. (1).

- For the extraction yield, response value $Y_{1}$, the MAE was the best solution: $23.50 \pm 4.3 \%$ was achieved at $11.1 \pm 1.2 \mathrm{~min}$ and $150 \pm 10.2^{\circ} \mathrm{C}$.

- For the ergosterol purity in the extract, response value $Y_{2}$, the UAE was the best solution: $1.92 \pm 0.2 \mathrm{mg} / 100 \mathrm{~g} \mathrm{E}$, was achieved at $30.0 \pm 1.5 \mathrm{~min}$ and $311.7 \pm 31.2 \mathrm{~W}$

- For the response yield in ergosterol, response value $Y_{3}$, the MAE was the best solution; $25.50 \pm 3.5 \mathrm{mg} / 100 \mathrm{~g} \mathrm{M} \mathrm{dw}$ was achieved at $25.0 \pm 3.4 \mathrm{~min}$ and $140.7 \pm 12.1^{\circ} \mathrm{C}$.

- The global optimal conditions found are as follow:

- For the response value $Y_{1}$, the MAE was the best solution: $21.16 \pm 2.3 \%$ was achieved at $25.0 \pm 2.6 \mathrm{~min}$ and $134.6 \pm 10.9^{\circ} \mathrm{C}$.

- For the response value $Y_{2}$, the UAE was the best solution: $1.77 \pm 0.6 \mathrm{mg} / 100 \mathrm{~g} \mathrm{E}$, was achieved at $30.0 \pm 4.3 \mathrm{~min}$ and $400.0 \pm 18.7 \mathrm{~W}$

- For the response value $Y_{3}$, the MAE was the best solution: $25.44 \pm 5.1 \mathrm{mg} / 100 \mathrm{~g} \mathrm{M} \mathrm{dw}$ was achieved at $25.0 \pm 2.6 \mathrm{~min}$ and $134.6 \pm 10.9^{\circ} \mathrm{C}$.

Considering both the individual and global values, the higher extract yield was obtained using the MAE technique. HAE also conducted to high extraction yields, but requiring higher extraction times. In terms of $Y_{2}$, UAE reached maximum results by consuming less energy and time, while providing higher ergosterol purity in the extract, which is aligned with the requirements of a green technology. The results herein obtained are in accordance with conclusions previously found (Chemat et al., 2017; Montesano et al., 2008; Zhu et al., 2016). UAE is an eco- friendly alternative to conventional techniques. The main benefits are the time and energy reduction, and type of applied solvents, consequently minimizing industrial emissions (Chemat et al., 2017), which is an objective of the sustainable "green" chemistry. The extraction processes are completed in minutes with high reproducibility, simplifying manipulation and work conditions, giving products with higher purity and eliminating further treatment as it occurs in conventional extraction methods such as Soxhlet extraction or maceration (Chemat et al., 2017).

\subsection{Optimization of solid-liquid extraction using HAE, MAE and UAE technique}

As already described elsewhere, the ideal $S / L$ should be one that allows the solvent to penetrate the structure of the solid matrix (Pinela et al., 2017), allowing also the solvent to dissolve all the target compounds (Albuquerque et al., 2016). Therefore, a study aiming to evaluate the $S / L$ effect was conducted at the global optimal conditions predicted by the polynomial models obtained for HAE, UAE, and MAE techniques (Table 3 part B). Preliminary experiments indicated a limit value of $S / L$ near to $120 \mathrm{~g} / \mathrm{L}$. Therefore, the dose-response analysis process was designed to analyze the $S / L$ from 5 to $120 \mathrm{~g} / \mathrm{L}$.

The dose-response results to the study of the $S / L$ effects for the three response value formats $\left(Y_{1}, Y_{2}\right.$, and $\left.Y_{3}\right)$, and each one of the used three techniques, was evaluated by fitting the Weibull model of Eq. (2) (in its increasing or decreasing form) to the obtained responses using nonlinear least-squares estimations. The obtained parametric values are presented in Table A2 (supplementary material). The effects caused by 


\section{A: JOIN ACTION (3D)}
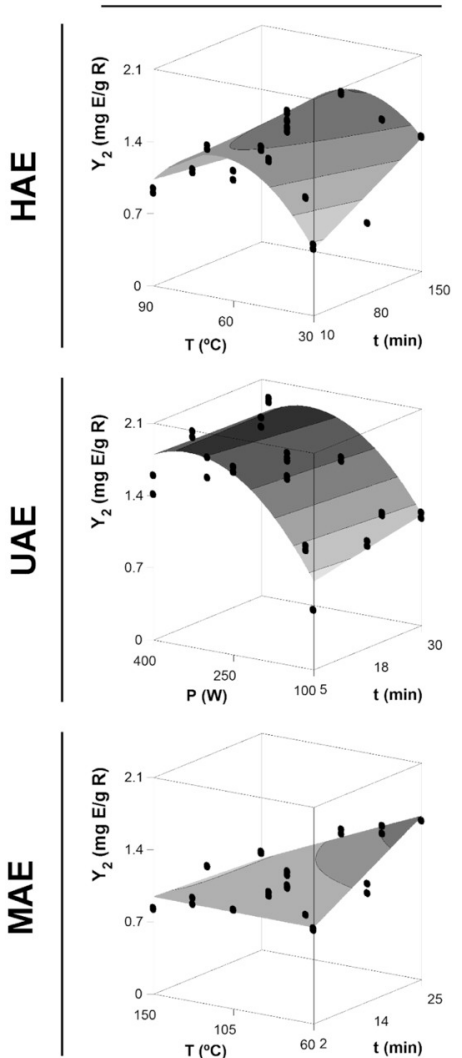
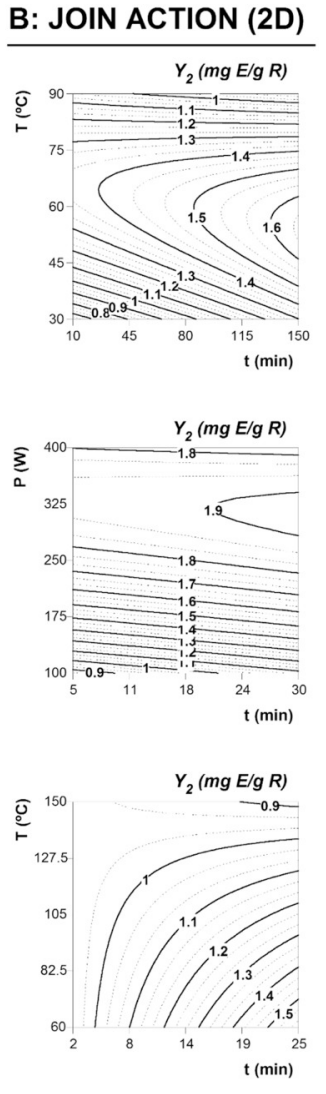

\section{C: STATISTICAL ANALYSIS}
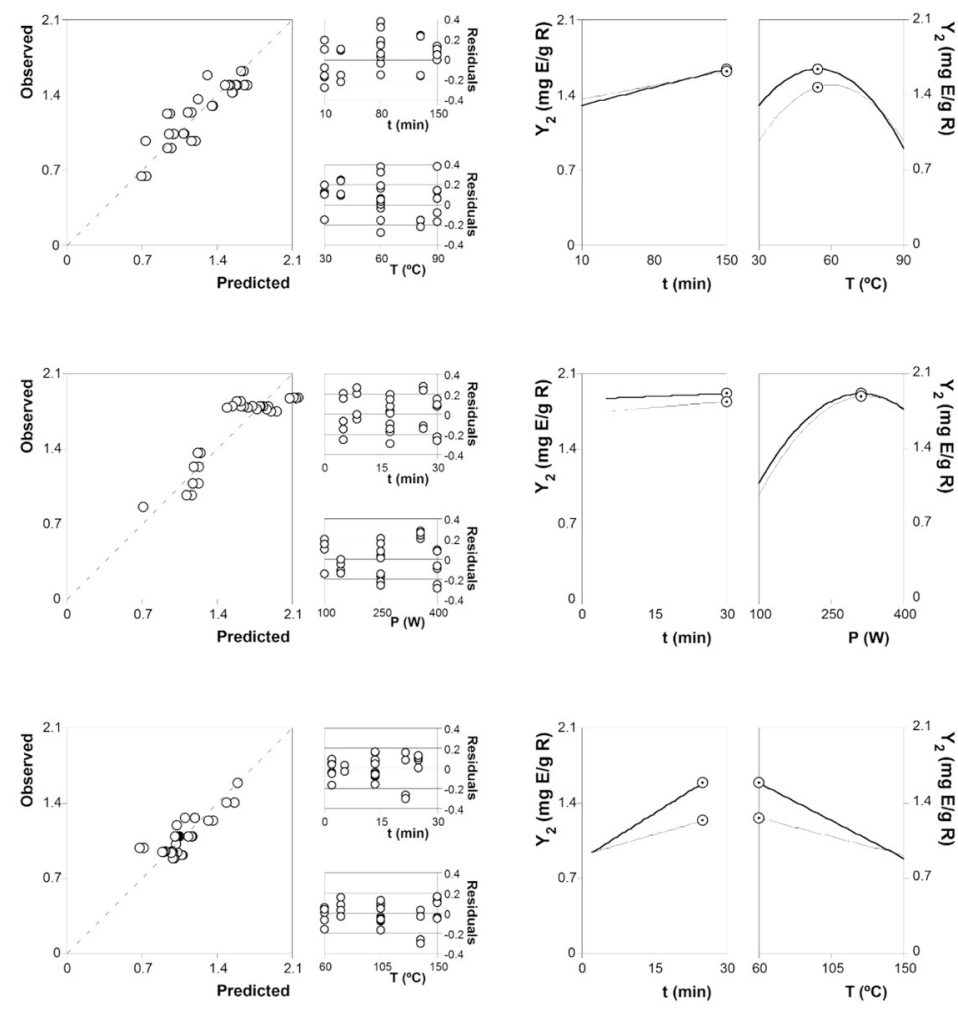

\section{D: OPTIMAL VALUES}
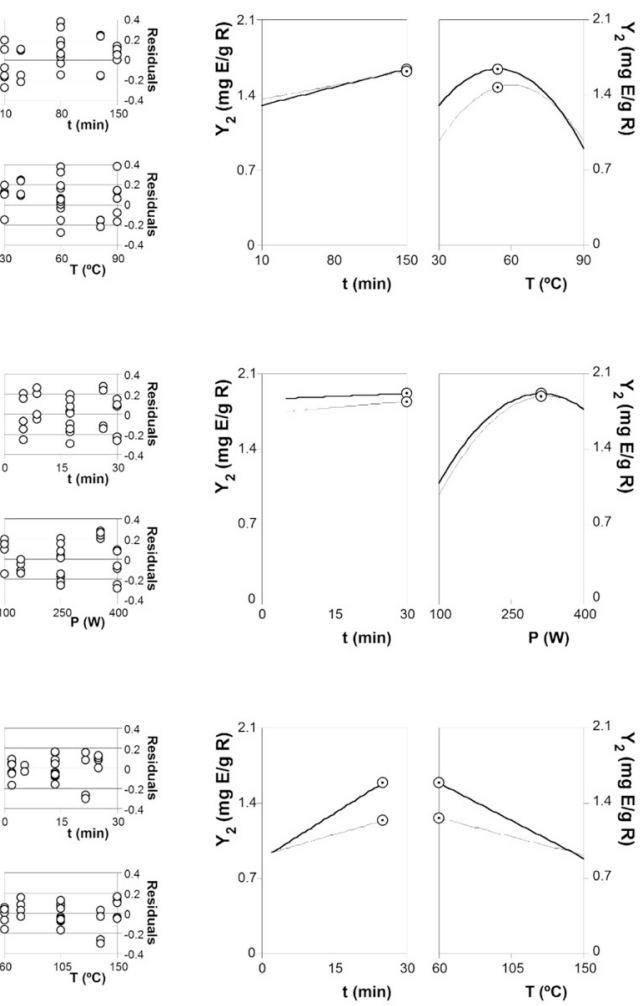

Fig. 3. Graphical results in terms of response value format $Y_{2}(\mathrm{mg} \mathrm{E} / \mathrm{g} \mathrm{R})$ using HAE, UAE and MAE extraction techniques. Part A: Points (•) represent the obtained experimental results (Table 1) and the net surface represents the theoretical 3D response surface predicted with the second order polynomial Eq. (1) as a function of each of the variables involved. Estimated parametric values of are shown in Table 2. Part B: Two-dimensional representation of the fitting results of Eq. (1). The binary actions between variables are presented when the excluded variable is positioned at the optimum of the experimental domain (Table 3). Part C: To illustrate the statistical description, two basic graphical criteria are used: the ability to simulate the changes of the response and the residual distribution as a function of each of the variables. Part $D$ : The dots $(\odot)$ presented alongside each line highlight the location of the optimum value. Lines are generated by Eq. (1).

the increase of the $S / L$ on the response value formats are graphically shown in Fig. 5 for the three studied techniques. Fig. 5 part A shows the experimental dose-response results (in which: $Y_{1} \bigcirc, Y_{2} \square$ and $Y_{3} \bullet$ ) at the global optimal values of the two variables defined for each of the three assessed techniques (HAE, UAE and MAE), and their respective predictions made by the mathematical model of Eq. (2) (lines). In general, a non-linear effect can be observed for all responses as the $S / L$ dose-response increases, causing a saturated-decreasing effect $(\downarrow)$ for the $Y_{1}(\mathrm{mg} \mathrm{C} / \mathrm{g} \mathrm{R})$ value format and saturated-increasing effects $(\uparrow)$ for the $Y_{2}(\mathrm{mg} \mathrm{C} / \mathrm{g} \mathrm{P} \mathrm{dw})$ and $Y_{3}(\mathrm{~g} \mathrm{R} / \mathrm{g} \mathrm{P} \mathrm{dw})$ value formats. Fig. 5B shows, jointly, the dose-response simulation trends for HAE, UAE and MAE for comparison purposes.

The analysis of the results can be interpreted by means of the two main parameters $K$ and $m_{n}$ (at $50 \%$ or $99 \%$ of the response). The parameter $K$ shows the maximum extraction value that can be obtained as a function of the $S / L$ dose-response. Thus, the lower the $m_{n}$ values are, the higher are the extraction levels reached in a shorter dose-response, what would limit the possibility of reducing the amount of needed solvent for industrial purposes. Given these considerations, both values are important to understand the trends of the $S / L$ dose-response effect. In a more detailed analysis, the following aspects can be observed:

- For $Y_{1}$ values, response that translates the extraction yield: a saturated-decreasing dose-response pattern was found, which means that $Y_{2}$ initially decreases to zero as $S / L$ increases. For HAE, UAE, and MAE the $m_{50 \%}$ values obtained were $41.14 \pm 4.51$, $53.85 \pm 6.28$, and $82.76 \pm 8.58 \mathrm{~g} / \mathrm{L}$, respectively, with a maximum extraction yield (parametric value of $K$ ) of $33.43 \pm 2.19$, $22.00 \pm 3.65$ and $26.98 \pm 3.51 \%$, for all the assessed techniques. The $R^{2}$ values obtained for the fitting results of the experimental values to Eq. (2) in its saturated-decreasing form $(\downarrow)$ were 0.9848 , 0.8604 and 0.9030 for HAE, UAE, and MAE, respectively.

- For $Y_{2}$ values, response that gives the ergosterol purity in the extracted: a saturated-increasing $(\uparrow)$ dose-response pattern was observed, which means that $Y_{1}$ initially increases as the $S / L$ increases, but when certain $S / L$ levels are reached the ergosterol purity in the extract remains constant. For HAE, the response increases until $S / L$ reaches values close to $155.46 \pm 12.61 \mathrm{~g} / \mathrm{L}$ (parametric value $m_{99 \%}$ from Eq. (2), Table A2, supplementary material), allowing a content of $2.57 \pm 0.63 \mathrm{mg} \mathrm{E} / \mathrm{g} \mathrm{R}$ (parametric value $K$ from Eq. (2), Table A2, Supplementary material). For UAE, the $m_{99 \%}$ value was $102.44 \pm 17.96 \mathrm{~g} / \mathrm{L}$, with a $K$ value of $2.92 \pm 0.33 \mathrm{mg} \mathrm{E} / \mathrm{g} \mathrm{R}$, and for MAE, $12.70 \pm 2.11 \mathrm{~g} / \mathrm{L}$ was obtained as $m_{99 \%}$, with $K$ giving $1.01 \pm 0.19 \mathrm{mg} \mathrm{E} / \mathrm{g}$ R. In HAE and MAE, the achieved increased levels of ergosterol purity by varying the $S / L$ are not as pronounced as those observed with UAE, a fact that may be related to instrumental limitations. The $R^{2}$ values obtained for the fitting results of the experimental values of Eq. (2) in its saturated-decreasing form $(\downarrow)$ were $0.9916,0.9750$ and 0.9363 for HAE, UAE, and MAE, respectively.

- For $Y_{3}$ values, response that reflects the yield in ergosterol: a saturated-increasing $(\uparrow)$ dose-response pattern was noticed, which means that $Y_{2}$ initially increases as the $S / L$ values increase. For HAE, $\mathrm{UAE}$, and MAE the $m_{99 \%}$ the obtained values were $25.34 \pm 2.17$, $36.35 \pm 2.25$, and $26.57 \pm 3.85 \mathrm{~g} / \mathrm{L}$, respectively, presenting $K$ 


\section{A: JOIN ACTION (3D)}
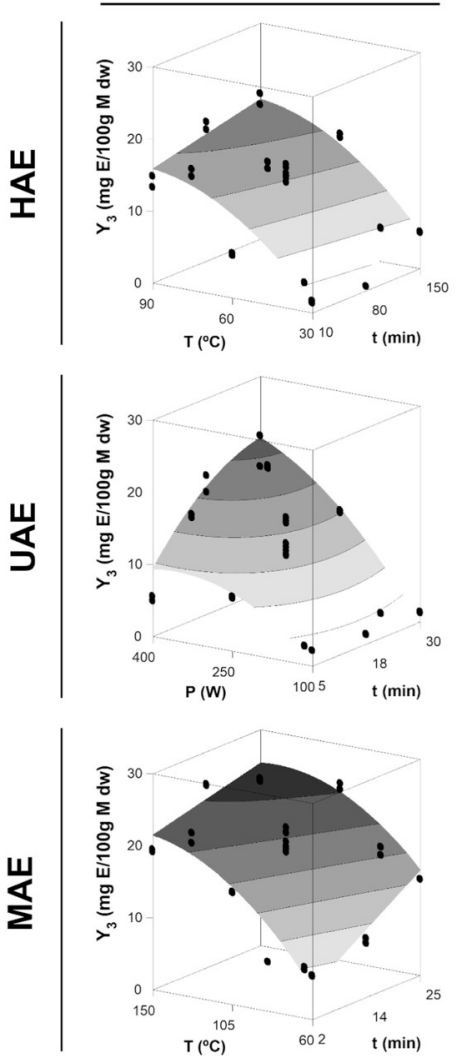

\section{B: JOIN ACTION (2D)}
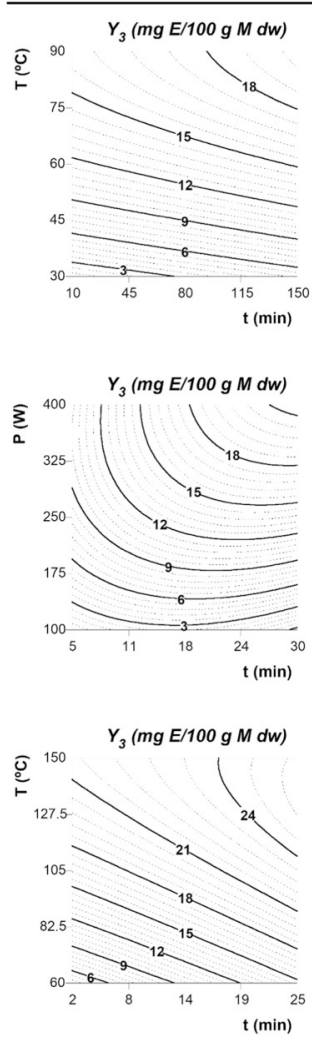

C: STATISTICAL ANALYSIS
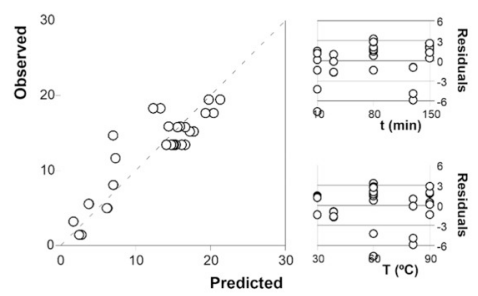

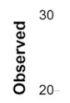
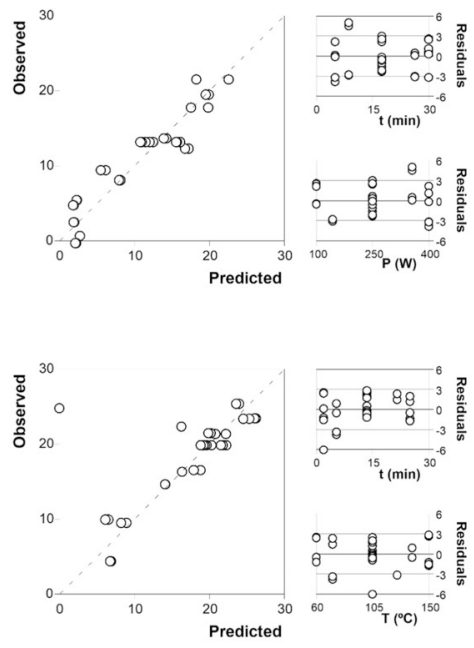

\section{D: OPTIMAL VALUES}
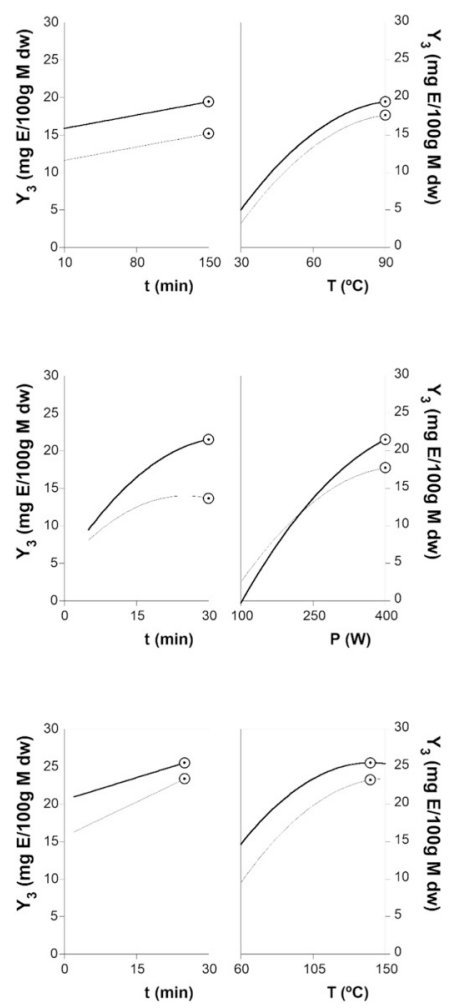

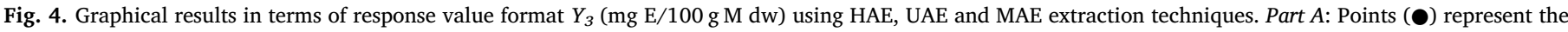

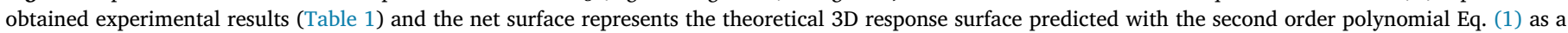

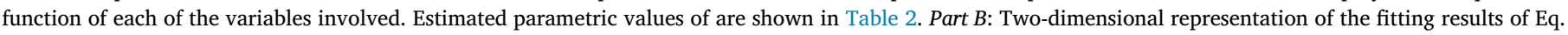

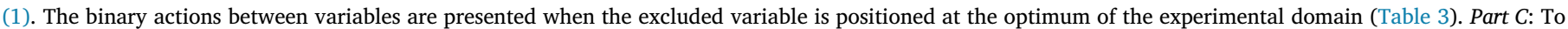

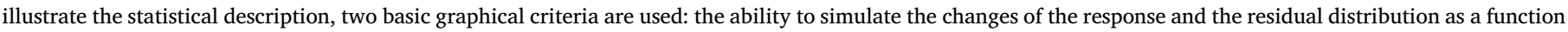
of each of the variables. Part D: The dots $(\odot)$ presented alongside each line highlight the location of the optimum value. Lines are generated by Eq. (1).

Table 3

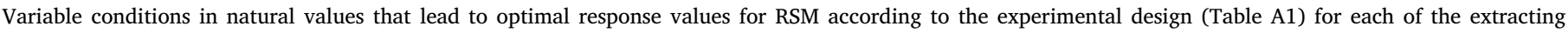

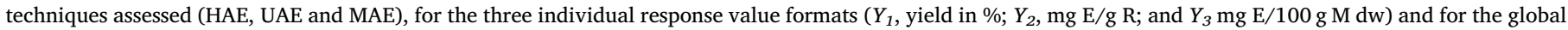
optimal conditions.

\begin{tabular}{|c|c|c|c|c|c|}
\hline \multirow[t]{2}{*}{ Criteria } & & \multicolumn{2}{|c|}{ Optimal variable conditions } & \multirow[t]{2}{*}{ Optimum response } & \\
\hline & & $\mathrm{X}_{1}: \mathrm{t}(\mathrm{min})$ & $\mathrm{X}_{2}: \mathrm{t}\left({ }^{\circ} \mathrm{c}\right)$ or $\mathrm{p}(\mathrm{w})$ & & \\
\hline \multicolumn{6}{|c|}{ A) Individual optimal variable conditions } \\
\hline \multirow[t]{3}{*}{ Maceration (ME) } & $Y_{1}$ & $150.0 \pm 5.3$ & $90.0 \pm 6.4$ & $19.37 \pm 1.2$ & $\%$ \\
\hline & $Y_{2}$ & $150.0 \pm 6.2$ & $54.3 \pm 7.1$ & $1.64 \pm 0.2$ & $m g E / g R$ \\
\hline & $Y_{3}$ & $150.0 \pm 4.9$ & $90.0 \pm 8.6$ & $19.43 \pm 3.1$ & $m g E / 100 g M d w$ \\
\hline \multirow[t]{3}{*}{ Ultrasound (UAE) } & $Y_{1}$ & $30.0 \pm 7.9$ & $400.0 \pm 15.2$ & $11.03 \pm 0.9$ & $\%$ \\
\hline & $Y_{2}$ & $30.0 \pm 1.5$ & $311.7 \pm 31.2$ & $1.92 \pm 0.2$ & $m g E / g R$ \\
\hline & $Y_{3}$ & $30.0 \pm 6.2$ & $400.0 \pm 51.1$ & $21.49 \pm 1.9$ & $m g E / 100 g M d w$ \\
\hline \multirow[t]{3}{*}{ Microwave (MAE) } & $Y_{1}$ & $11.1 \pm 1.2$ & $150.0 \pm 10.2$ & $23.50 \pm 4.3$ & $\%$ \\
\hline & $Y_{2}$ & $25.0 \pm 4.2$ & $60.0 \pm 11.5$ & $1.59 \pm 0.4$ & $m g E / g R$ \\
\hline & $Y_{3}$ & $25.0 \pm 3.4$ & $140.7 \pm 12.1$ & $25.50 \pm 3.5$ & $m g E / 100 g M d w$ \\
\hline \multicolumn{6}{|c|}{ B) Global optimal variable conditions } \\
\hline \multirow[t]{3}{*}{ Maceration (ME) } & $Y_{1}$ & $150.0 \pm 6.1$ & $81.6 \pm 2.6$ & $17.05 \pm 1.9$ & $\%$ \\
\hline & $Y_{2}$ & & & $1.21 \pm 0.1$ & $m g E / g R$ \\
\hline & $Y_{3}$ & & & $18.84 \pm 2.3$ & $m g E / 100 g M d w$ \\
\hline \multirow[t]{3}{*}{ Ultrasound (UAE) } & $Y_{1}$ & $30.0 \pm 4.3$ & $400.0 \pm 18.7$ & $11.03 \pm 3.1$ & $\%$ \\
\hline & $Y_{2}$ & & & $1.77 \pm 0.6$ & $m g E / g R$ \\
\hline & $Y_{3}$ & & & $21.49 \pm 0.9$ & $m g E / 100 g M d w$ \\
\hline \multirow[t]{3}{*}{ Microwave (MAE) } & $Y_{1}$ & $25.0 \pm 2.6$ & $134.6 \pm 10.9$ & $21.16 \pm 2.3$ & $\%$ \\
\hline & $Y_{2}$ & & & $1.01 \pm 0.1$ & $m g E / g R$ \\
\hline & $Y_{3}$ & & & $25.44 \pm 5.1$ & $m g E / 100 g M d w$ \\
\hline
\end{tabular}




\section{A: FITTING ANALYSIS OF ALL RESPONSES}

\section{Heat-assisted extraction (HAE)}

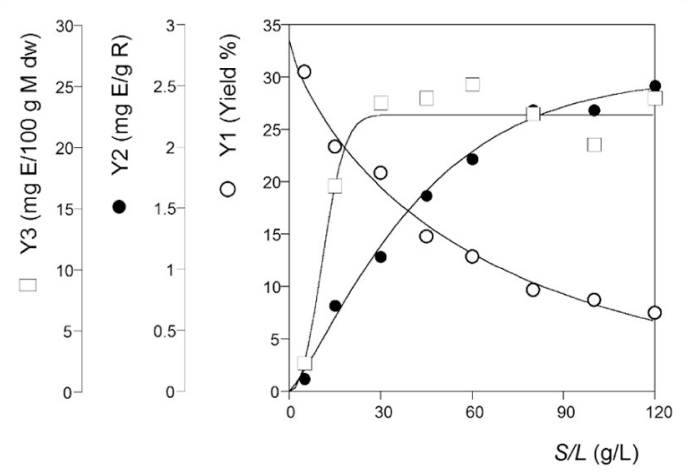

Ultrasound-assisted extraction (UAE)

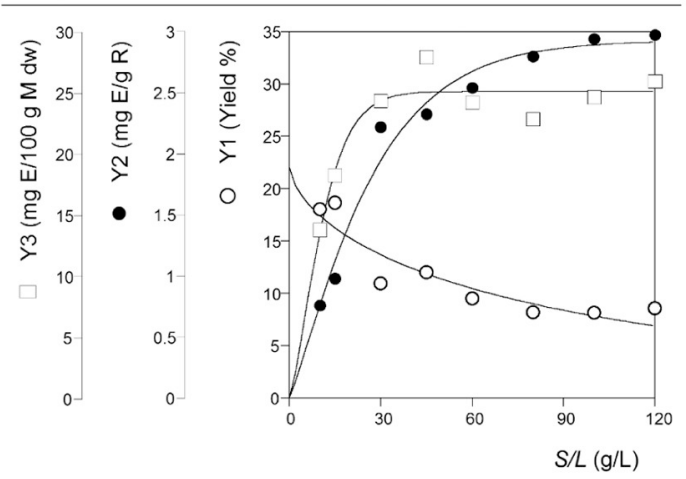

Microwave-assisted extraction (MAE)

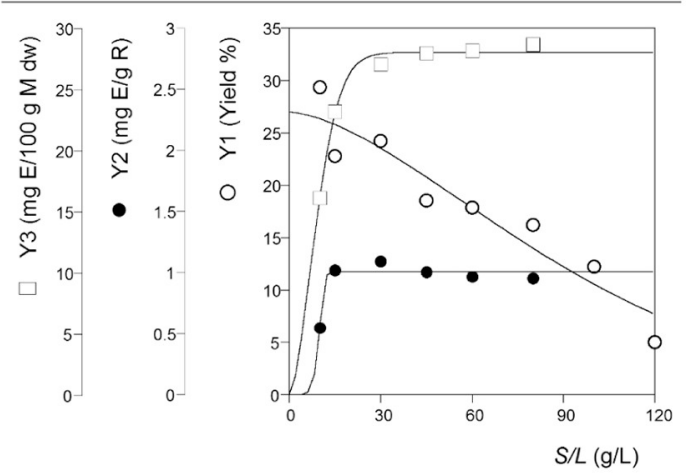

\section{B: SIMULATION ANALYSIS OF THE RESPONSES}
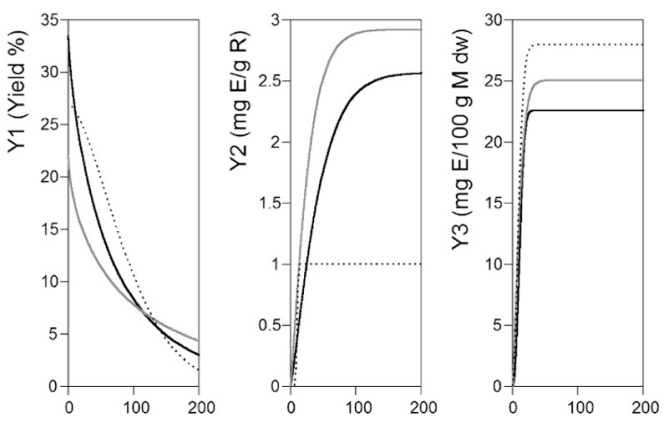

$S / L(g / L)$

$S / L(g / L)$

HAE UAE MAE $\quad$ M........

Fig. 5. Graphical illustration of the effects caused by the $S / L$ on the response value formats for the three studied techniques. Part $A$ shows the fitting analysis of the experimental dose-response results (in which: $Y \bigcirc Y_{2} \square$ and $Y_{3} \bullet$ ) at the global optimal values of the two other variables for each of the three techniques assessed (HAE, UAE and MAE) and their respective predictions made by the mathematical model of Eq. (2) (lines). Meanwhile, part B shows the dose-response simulation trends for HAE, UAE and MAE jointly for comparison purposes.

values of $22.60 \pm 3.45,25.07 \pm 4.12$ and $28.01 \pm 3.76 \mathrm{C}$ / $100 \mathrm{~g} \mathrm{M} \mathrm{dw}$, respectively. These results may reflect the total ergosterol content available in the mushroom fruiting body, once the maximum concentration is achieved. In the non-conventional techniques (UAE and MAE) the decreasing effect is less noticeable, comparatively with the used conventional extraction method (HAE). In fact, for UAE and MAE the $S / L$ effect remains almost constant until $\sim 120 \mathrm{~g} / \mathrm{L}$.

In conclusion, UAE was the best extraction technique, closely followed by MAE. The less effective extraction system was HAE. These results prove that alternative solid-liquid extraction methods are more suitable than the conventional ones for the extraction of ergosterol from ABM fruiting bodies. The findings of this work are in accordance with the ones of Tomšik et al. (2016), which stated that UAE enhances the extraction process by increasing the mass transfer between the solvent and the plant material. The collapse of cavitation bubbles leads to a better cell disruption facilitating the release of extractable compounds, allowing a greater penetration of solvent into the sample matrix, thus increasing the contact surface area between the solid and liquid phase (Chemat et al., 2017; Tomšik et al., 2016).

3.4. Comparison of the efficiency of ergosterol extraction by conventional and non-conventional techniques

Chemical synthesis of ergosterol and other valuable sterols can be carried out by chemical esterification and lipase-catalyzed esterification that requires several energy and material consuming steps (He et al., 2014). Production of these valuable ingredients using these routes presents disadvantages, making alternative processes, such as extraction from ergosterol-rich matrices, attractive methods for ergosterol obtainment. Several authors have reported the extraction of ergosterol from mushrooms using the Soxhlet system (Barreira et al., 2013; Heleno, Diz, et al., 2016a; Taofiq et al., 2016). Agaricus bisporus (J.E.Lange) Imbacha and other edible or medicinal mushrooms belonging to the Agaricus genus have been reported to be novel sources of ergosterol (Table 4). A. bisporus presented the higher content of ergosterol (Deng et al., 2017), when compared to other species, however, A. blazei can be valorized as a viable source of ergosterol, considering the surplus amount of its fruiting bodies that are discarded in the production/processing chain. From previous studies also reported in Table 4, extraction of ergosterol has been carried out using conventional techniques, as well as non-conventional methods, with the latter requiring milder conditions. Most of the methods reported in Table 4 were conducted using one variable at a time, what in most cases does not guarantee maximization of the ergosterol recovery. Hence, carrying out RSM using a series of experimental domains, and possible combination of independent variables, presents advantages (Heleno, Diz, et al., 2016; Heleno, Prieto, et al., 2016).

Conventional techniques such as SE and HAE have been used for decades requiring large solvent consumption and being high timeconsuming processes, leading often to the degradation of compounds with health-related risks (Heleno, Diz, et al., 2016a). However, nonconventional extraction techniques such as the UAE and the MAE are being applied to maximize the extraction of several valuable compounds from natural matrices using shorter times and with high 
Table 4

Ergosterol content reported in some Agaricus genus.

\begin{tabular}{|c|c|c|c|c|c|c|c|}
\hline \multirow[t]{2}{*}{ Technique } & \multicolumn{2}{|l|}{ Plant material } & \multicolumn{2}{|l|}{ Solvent } & \multirow[t]{2}{*}{ Conditions } & \multirow[t]{2}{*}{ Content (mg e/100 g) } & \multirow[t]{2}{*}{ Reference } \\
\hline & Source & Used part & Type & Proportion (\%) & & & \\
\hline HAE & Agaricus bisporus & Mycelium & Methanol & 100 & $25^{\circ} \mathrm{C}, 1 \mathrm{~h}$, non-saponified & $17.49 \pm 1.45$ & (Cardoso et al., 2017) \\
\hline HAE & Agaricus bisporus & Fruiting bodies & Ethanol & 95 & $1 \mathrm{M} \mathrm{NaOH}, 80^{\circ} \mathrm{C}, 1 \mathrm{~h}$ saponified & $33.54 \pm 6.34$ & (Shao et al., 2010) \\
\hline HAE & Agaricus bisporus $\mathrm{P}$ & Fruiting bodies & Ethanol & 95 & $1 \mathrm{M} \mathrm{NaOH}, 80^{\circ} \mathrm{C}, 1 \mathrm{~h}$ saponified & $48.24 \pm 3.12$ & (Shao et al., 2010) \\
\hline HAE & Agaricus bisporus & Fruiting bodies & Ethanol & 95 & $80^{\circ} \mathrm{C}, 1 \mathrm{~h}$, saponified & $43.22 \pm 5.11$ & (Lee \& Aan, 2016) \\
\hline HAE & Agaricus arvensis & Fruiting bodies & Methanol & 100 & $2 \mathrm{M} \mathrm{NaOH}$, saponified & $26.83 \pm 8.71$ & (Gąsecka et al., 2017) \\
\hline HAE & Agaricus bisporus $\mathrm{P}$ & Fruiting bodies & Methanol & 100 & $2 \mathrm{M} \mathrm{NaOH}$, saponified & $26.46 \pm 1.52$ & (Gąsecka et al., 2017) \\
\hline HAE & Agaricus bisporus & Fruiting bodies & Methanol & 100 & $2 \mathrm{M} \mathrm{NaOH}$, saponified & $1.15 \pm 36.16$ & (Gąsecka et al., 2017) \\
\hline HAE & Agaricus bitorquis & Fruiting bodies & Methanol & 100 & $2 \mathrm{M} \mathrm{NaOH}$, saponified & $35.35 \pm 0.55$ & (Gąsecka et al., 2017) \\
\hline HAE & Agaricus brasiliensis & Fruiting bodies & Methanol & 100 & $2 \mathrm{M} \mathrm{NaOH}$, saponified & $6.01 \pm 0.32$ & (Gąsecka et al., 2017) \\
\hline HAE & Agaricus campestris & Fruiting bodies & Methanol & 100 & $2 \mathrm{M} \mathrm{NaOH}$, saponified & $42.34 \pm 0.48$ & (Gąsecka et al., 2017) \\
\hline HAE & Agaricus silvaticus & Fruiting bodies & Methanol & 100 & $2 \mathrm{M} \mathrm{NaOH}$, saponified & $45.82 \pm 2.11$ & (Gąsecka et al., 2017) \\
\hline PLE & Agaricus bisporus & Fruiting bodies & Ethanol & - & $10.68 \mathrm{MPa}, 50^{\circ} \mathrm{C}$ & $93.06 \pm 4.21$ & (Gil-Ramírez et al., 2013) \\
\hline CAE & Agaricus bisporus & Fruiting bodies & Hexane & - & $4000 \mathrm{rpm}, 10 \mathrm{~min}$ & $612.65 \pm 9.45$ & (Guan et al., 2016) \\
\hline CAE & Agaricus bisporus $\mathrm{P}$ & Fruiting bodies & Hexane & - & $4000 \mathrm{rpm}, 10 \mathrm{~min}$ & $759.34 \pm 13.56$ & (Guan et al., 2016) \\
\hline CAE & Agaricus brazilienses & Mycelium & Ethanol & 95 & $4000 \mathrm{rpm}, 20 \mathrm{~min}$ & $74.67 \pm 4.87$ & (Gao \& Gu, 2007) \\
\hline MAE & Agaricus bisporus & Fruiting bodies & Ethanol & - & $19.4 \mathrm{~min}, 132.8^{\circ} \mathrm{C}$ & $555.3 \pm 23.6$ & (Heleno, Prieto, et al., 2016) \\
\hline SFAE & Agaricus bisporus & Fruiting bodies & Ethanol & 10 & $9-30 \mathrm{MPa}, 40^{\circ} \mathrm{C}$ & $532.45 \pm 4.85$ & (Gil-Ramírez et al., 2013) \\
\hline UAE & Agaricus bisporus & Fruiting bodies & Ethanol & 100 & $15 \mathrm{~min}, 375 \mathrm{~W}$ & $19.49 \pm 0.74$ & (Francisco et al., 2018) \\
\hline UAE & Agaricus bisporus & Fruiting bodies & Hexane & & $15 \mathrm{~min}, 375 \mathrm{~W}$ & $152.22 \pm 6.53$ & (Heleno, Diz, et al., 2016) \\
\hline UAE & Agaricus bisporus & Fruiting bodies & Ethanol & 100 & $15 \mathrm{~min}, 375 \mathrm{~W}$ & $671.53 \pm 10.51$ & (Heleno, Diz, et al., 2016) \\
\hline UAE & Agaricus bisporus & Fruiting bodies & Limonene & - & $15 \mathrm{~min}, 375 \mathrm{~W}$ & $372.02 \pm 0.17$ & (Heleno, Diz, et al., 2016) \\
\hline UAE & Agaricus bisporus & Fruiting bodies & Ethanol & 100 & 15 mins, $375 \mathrm{~W}$ & $36.72 \pm 0.01$ & (Heleno, Prieto, et al., 2016) \\
\hline SE & Agaricus blazei & Fruiting bodies & Ethanol & 100 & $4 \mathrm{~h}, 5$ cycles & $58.53 \pm 1.72$ & (Corrêa et al., 2018) \\
\hline SE & Agaricus bisporus $\mathrm{P}$ & Fruiting bodies & Hexane & 100 & $2 \mathrm{~h}$ & $77.34 \pm 1.45$ & (Barreira et al., 2013) \\
\hline SE & Agaricus bisporus & Fruiting bodies & Hexane & 100 & $2 \mathrm{~h}$ & $352.32 \pm 1.64$ & (Barreira et al., 2013) \\
\hline SE & Agaricus bisporus & Fruiting bodies & Hexane & 100 & $4 \mathrm{~h}, 12$ cycles & $186.11 \pm 0.33$ & (Heleno, Diz, et al., 2016) \\
\hline SE & Agaricus bisporus & Fruiting bodies & Ethanol & 100 & $4 \mathrm{~h}, 12$ cycles & $676.12 \pm 31.23$ & (Heleno, Diz, et al., 2016) \\
\hline SE & Agaricus bisporus & Fruiting bodies & Limonene & 100 & $4 \mathrm{~h}, 12$ cycles & $261.86 \pm 11.75$ & (Heleno, Diz, et al., 2016) \\
\hline SE & Agaricus bisporus & Fruiting bodies & Ethanol & 100 & $4 \mathrm{~h}, 12$ cycles & $44.79 \pm 0.37$ & (Taofiq, Heleno, et al., 2016) \\
\hline
\end{tabular}

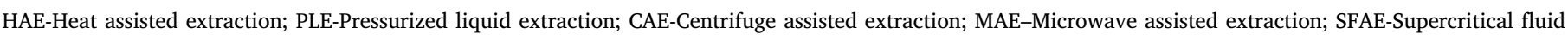
assisted extraction; UAE-Ultrasound assisted extraction, SE- Soxhlet extraction. P - Portobello.

reproducibility (Rezende, Nogueira, \& Narain, 2017). The MAE optimum conditions provided the highest extraction yield, while the UAE under the optimum achieved conditions conducted to the highest ergosterol purity in the extract.

\section{Conclusions}

The simplicity of using conventional extraction methodologies (HAE or maceration) $v s$ the advantages of using non-conventional technologies (microwave, ultrasound) to recover bioactive compounds from natural matrices, from an environmental and economical point of view, has received special attention in the last decades. In the present study, the optimum conditions of ( $t, T$ and P; depending on the chosen technique), to recover ergosterol from A. blazei using HAE, MAE and UAE were established using RSM. The results showed that the optimum conditions to maximize responses lie in the selected experimental domains that were selected. The response values predicted by the model are in close agreement with the experimental observations, proving the validity of the model and the utility of the predictions for future scale up to obtain ergosterol-rich extracts from ABM. The UAE technology, at the optimum conditions, was identified as the most appropriate to obtain high content ergosterol-rich extracts, followed by MAE and HAE. The obtained ergosterol-rich extracts can be applied as bioactive ingredients for food, pharmaceutical, cosmeceutical and nutraceutical purposes.

\section{Acknowledgements}

The authors are grateful to the Foundation for Science and Technology (FCT, Portugal) and FEDER under Programme PT2020 for financial support to CIMO (UID/AGR/00690/2019); L. Barros thanks national funding by FCT, P.I., through the individual scientific employment program-contract for her contract; to the European Regional Development Fund (ERDF) through the Regional Operational Program North 2020, within the scope of Project MobilizadorNorte-010247-FEDER-024479: ValorNatural ${ }^{\oplus}$; to European Structural and Investment Funds (FEDER), through the Rural Development Program (PDR2020), within the scope of Project MicoCoating (PDR2020-101031472). The authors thank the GAIN (Xunta de Galicia) for financial support (P.P. 0000 421S 140.08) to M.A. Prieto by a post-doctoral (modality B) grant. R.C.G. Correa thanks CAPES Foundation, Ministry of Education, Brazil (CAPES fellow, process number 88881.120010/ 2016-01), for the financial support provided for her postdoctoral research in Polytechnic Institute of Bragança. Rosane Marina Peralta and Adelar Bracht are recipients of scientific productivity research grants from $\mathrm{CNPq}$ (Conselho Nacional de Desenvolvimento Científico e Tecnológico, Brazil), grants numbers 307944/2015-8 and 304090/ 2016-6, respectively. To project POCI-01-0145-FEDER-006984 Associate Laboratory LSRE-LCM funded by FEDER through COMPETE2020-POCI and by FCT.

\section{Appendix A. Supplementary data}

Supplementary data to this article can be found online at https:// doi.org/10.1016/j.foodres.2019.108541.

\section{References}

Albuquerque, B. R., Prieto, M. A., Barreiro, M. F., Rodrigues, A., Curran, T. P., Barros, L., \& Ferreira, I. C. F. R. (2016). Catechin-based extract optimization obtained from Arbutus unedo L. fruits using maceration/microwave/ultrasound extraction techniques. Industrial Crops and Products, 95, 404-415.

Barreira, J. C. M., Oliveira, M. B. P. P., \& Ferreira, I. C. F. R. (2013). Development of a novel methodology for the analysis of Ergosterol in mushrooms. Food Analytical Methods, 7(1), 217-223. https://doi.org/10.1007/s12161-013-9621-9.

Bezerra, M. A., Santelli, R. E., Oliveira, E. P., Villar, L. S., Escaleira, E. A., \& Escaleira, L. A. 
(2008). Response surface methodology (RSM) as a tool for optimization in analytical chemistry. Talanta, 76(5), 965-977.

Cardoso, R. V. C., Fernandes, Â., Oliveira, M. B. P. P., Calhelha, R. C., Barros, L., Martins, A., \& Ferreira, I. C. F. R. (2017). Development of nutraceutical formulations based on the mycelium of Pleurotus ostreatus and Agaricus bisporus. Food Functions, 8(6), 2155-2164.

Chemat, F., Rombaut, N., Sicaire, A. G., Meullemiestre, A., Fabiano-Tixier, A. S., \& AbertVian, M. (2017). Ultrasound assisted extraction of food and natural products. Mechanisms, techniques, combinations, protocols and applications. A review. Ultrasonics Sonochemistry, 34, 540-560.

Chen, X., Huynh, N., Cui, H., Zhou, P., Zhang, X., \& Yang, B. (2018). Correlating supercritical fluid extraction parameters with volatile compounds from Finnish wild mushrooms (Craterellus tubaeformis) and yield prediction by partial least squares regression analysis. RSC Advances, 8(10), 5233-5242. https://doi.org/10.1039/ C7RA12472D.

Corrêa, R., Barros, L., Fernandes, A., Sokovic, M., Brachtc, A., Peralta, R. M., \& Ferreira, I. C. F. R. (2018). A natural food ingredient based on ergosterol: Optimization of the extraction from Agaricus blazei, evaluation of bioactive properties and incorporation in yogurts. Food \& Function, 1465-1474. https://doi.org/10.1039/C7FO02007D.

Corrêa, R. C. G., Peralta, R. M., Bracht, A., \& Ferreira, I. C. F. R. (2017). The emerging use of mycosterols in food industry along with the current trend of extended use of bioactive phytosterols. Trends in Food Science and Technology, 67, 19-35. https://doi. org $/ 10.1016 / j . t i f s .2017 .06 .012$.

Deng, J., Xu, Z., Xiang, C., Liu, J., Zhou, L., Li, T., ... Ding, C. (2017). Comparative evaluation of maceration and ultrasonic-assisted extraction of phenolic compounds from fresh olives. Ultrasonics Sonochemistry, 37, 328-334. https://doi.org/10.1016/j. ultsonch.2017.01.023.

Elliot, G. G., Shahin, W., Garcia-garcia, G., White, R., \& Needham, L. (2017). A methodology for sustainable management of food waste. Waste and Biomass Valorization, 8(6), 2209-2227. https://doi.org/10.1007/s12649-016-9720-0.

Ferreira, I. C. F. R., Heleno, S. A., Reis, F. S., Stojkovic, D., Queiroz, M. J. R. P., Vasconcelos, M. H., \& Sokovic, M. (2015). Chemical features of Ganoderma polysaccharides with antioxidant, antitumor and antimicrobial activities. Phytochemistry, 114, 38-55. https://doi.org/10.1016/j.phytochem.2014.10.011.

Firenzuoli, F., Gori, L., \& Lombardo, G. (2008). The medicinal mushroom Agaricus blazei murrill: Review of literature and pharmaco-toxicological problems. Evidence-based Complementary and Alternative Medicine, 5(1), 3-15. https://doi.org/10.1093/ecam/ nem007.

Francisco, C. R. L., Heleno, S. A., Fernandes, I. P. M., Barreira, J. C. M., Calhelha, R. C., Barros, L., \& Barreiro, M. F. (2018). Functionalization of yogurts with Agaricus bisporus extracts encapsulated in spray-dried maltodextrin crosslinked with citric acid Food Chemistry, 245, 845-853.

Gao, H., \& Gu, W. Y. (2007). Optimization of polysaccharide and ergosterol production from Agaricus brasiliensis by fermentation process. Biochemical Engineering Journal, 33(3), 202-210.

Gąsecka, M., Magdziak, Z., Siwulski, M., \& Mleczek, M. (2017). Profile of phenolic and organic acids, antioxidant properties and ergosterol content in cultivated and wild growing species of Agaricus. European Food Research and Technology, 244(2), 1-10.

Gil-Ramírez, A., Aldars-García, L., Palanisamy, M., Jiverdeanu, R. M., Ruiz-Rodríguez, A., Marín, F. R., ... Soler-Rivas, C. (2013). Sterol enriched fractions obtained from Agaricus bisporus fruiting bodies and by-products by compressed fluid technologies (PLE and SFE). Innovative Food Science and Emerging Technologies, 18, 101-107. https://doi.org/10.1016/j.ifset.2013.01.007.

Guan, W., Zhang, J., Yan, R., Shao, S., Zhou, T., Lei, J., \& Wang, Z. (2016). Effects of UV-C treatment and cold storage on ergosterol and Vitamin D2 contents in different parts of white and brown mushroom (Agaricus bisporus). Food Chemistry, 210, 129-134.

He, W. S., Yin, J., Xu, H. S., Qian, Q. Y., Jia, C. S., Le Ma, H., \& Feng, B. (2014). Efficient synthesis and characterization of ergosterol laurate in a solvent-free system. Journal of Agricultural and Food Chemistry, 62(48), 11748-11755. https://doi.org/10.1021/ jf504516q.

Heleno, S. A., Diz, P., Prieto, M. A., Barros, L., Rodrigues, A., Barreiro, M. F., \& Ferreira, I. C. F. R. (2016), Optimization of ultrasound-assisted extraction to obtain mycosterols from Agaricus bisporus L. by response surface methodology and comparison with conventional Soxhlet extraction. Food Chemistry, 197, 1054-1063.

Heleno, S. A., Prieto, M. A., Barros, L., Rodrigues, A. A., Barreiro, M. F., \& Ferreira, I. C. F. R. (2016). Optimization of microwave-assisted extraction of ergosterol from Agaricus bisporus L. by-products using response surface methodology. Food and Bioproducts Processing, 100, 25-35.

Jiménez, L., Caleja, C., Prieto, M. A., Barreiro, M. F., Barros, L., \& Ferreira, I. C. F. (2018). Optimization and comparison of heat and ultrasound assisted extraction techniques to obtain anthocyanin compounds from Arbutus unedo L. fruits. Food Chemistry, 264, $81-91$.

Kang, J. H., Jang, J. E., Mishra, S. K., Lee, H. J., Nho, C. W., Shin, D., ... Oh, S. H. (2015). Ergosterol peroxide from Chaga mushroom (Inonotus obliquus) exhibits anti-cancer activity by down-regulation of the $\beta$-catenin pathway in colorectal cancer. Journal of Ethnopharmacology, 173, 303-312. https://doi.org/10.1016/j.jep.2015.07.030.

Lee, N. K., \& Aan, B.-Y. (2016). Optimization of ergosterol to vitamin D2 synthesis in Agaricus bisporus powder using ultraviolet-B radiation. Food Science and Biotechnology, 25(6), 1627-1631.

Lima, C. U. J. O., Gris, E. F., \& Karnikowski, M. G. O. (2016). Antimicrobial properties of the mushroom Agaricus blazei - Integrative review. Revista Brasileira de Farmacognosia, 26(6), 1-7. https://doi.org/10.1016/j.bjp.2016.05.013.
Montesano, D., Fallarino, F., Cossignani, L., Bosi, A., Simonetti, M. S., Puccetti, P., \& Damiani, P. (2008). Innovative extraction procedure for obtaining high pure lycopene from tomato. European Food Research and Technology, 226(3), 327-335.

Pinela, J., Prieto, M. A., Barreiro, M. F., Carvalho, A. M., Oliveira, M. B. P. P., Curran, T P., \& Ferreira, I. C. F. R. (2017). Valorisation of tomato wastes for development of nutrient-rich antioxidant ingredients: A sustainable approach towards the needs of the today's society. Innovative Food Science and Emerging Technologies. https://doi.org/ 10.1016/j.ifset.2017.02.004.

Pinela, J., Prieto, M. A., Barreiro, M. F., Carvalho, A. M., Oliveira, M. B. P. P., Vázquez, J. A., \& Ferreira, I. C. F. R. (2016a). Optimization of microwave-assisted extraction of hydrophilic and lipophilic antioxidants from a surplus tomato crop by response surface methodology. Food and Bioproducts Processing, 98, 283-298.

Pinela, J., Prieto, M. A. A., Carvalho, A. M., Barreiro, M. F., Oliveira, M. B. P., Barros, L., \& Ferreira, I. C. F. R. (2016b). Microwave-assisted extraction of phenolic acids and flavonoids and production of antioxidant ingredients from tomato: A nutraceuticaloriented optimization study. Separation and Purification Technology, 164, 114-124.

Prieto, M. A., Curran, T. P., Gowen, A., \& Vázquez, J. A. A. (2015). An efficient methodology for quantification of synergy and antagonism in single electron transfer antioxidant assays. Food Research International, 67, 284-298.

Ranic, M., Nikolic, M., Pavlovic, M., Buntic, A., Siler-Marinkovic, S., \& DimitrijevicBrankovic, S. (2014). Optimization of microwave-assisted extraction of natural antioxidants from spent espresso coffee grounds by response surface methodology. Journal of Cleaner Production, 80, 69-79.

Rezende, Y. R. R. S., Nogueira, J. P., \& Narain, N. (2017). Comparison and optimization of conventional and ultrasound assisted extraction for bioactive compounds and antioxidant activity from agro-industrial acerola (Malpighia emarginata DC) residue. LWT - Food Science and Technology, 85, 158-169. https://doi.org/10.1016/j.lwt.2017.07. 020 .

Roriz, C. L., Barros, L., Prieto, M. A., Morales, P., \& Ferreira, I. C. F. R. (2017). Floral parts of Gomphrena globosa L. as a novel alternative source of betacyanins: Optimization of the extraction using response surface methodology. Food Chemistry, 229, 223-234.

Shao, S., Hernandez, M., Kramer, J. K. G. J. K. G., Rinker, D. L. D. L., \& Tsao, R. (2010). Ergosterol profiles, fatty acid composition, and antioxidant activities of button mushrooms as affected by tissue part and developmental stage. Journal of Agricultural and Food Chemistry, 58, 11616-11625.

Shimizu, T., Kawai, J., Ouchi, K., Kikuchi, H., Osima, Y., \& Hidemi, R. (2016). Agarol, an ergosterol derivative from Agaricus blazei, induces caspase-independent apoptosis in human cancer cells. International Journal of Oncology, 48(4), 1670-1678. https://doi org/10.3892/ijo.2016.3391.

Soares, A. A., de Souza, C. G. M., Daniel, F. M., Ferrari, G. P., da Costa, S. M. G., \& Peralta, R. M. (2009). Antioxidant activity and total phenolic content of Agaricus brasiliensis (Agaricus blazei Murril) in two stages of maturity. Food Chemistry, 112(4), 775-781. https://doi.org/10.1016/j.foodchem.2008.05.117.

Taofiq, O., González-Paramás, A. M., Martins, A., Barreiro, M. F., \& Ferreira, I. C. F. R. (2016). Mushrooms extracts and compounds in cosmetics, cosmeceuticals and nutricosmetics-A review. Industrial Crops and Products, 90, 38-48. https://doi.org/10 1016/j.indcrop.2016.06.012.

Taofiq, O., Heleno, S., Calhelha, R., Alves, M., Barros, L., Barreiro, M., ... Ferreira, I. (2016). Development of mushroom-based Cosmeceutical formulations with anti-inflammatory, anti-Tyrosinase, antioxidant, and antibacterial properties. Molecules, 21(10), 1372. https://doi.org/10.3390/molecules21101372.

Taofiq, O., Martins, A., Barreiro, M. F., \& Ferreira, I. C. F. R. (2016). Anti-inflammatory potential of mushroom extracts and isolated metabolites. Trends in Food Science and Technology, 50, 193-210. https://doi.org/10.1016/j.tifs.2016.02.005.

Thirugnanasambandham, K., \& Sivakumar, V. (2017). Influence of process conditions on the physicochemical properties of pomegranate juice in spray drying process: Modelling and optimization. Journal of the Saudi Society of Agricultural Sciences, 16(4), 358-366. https://doi.org/10.1016/j.jssas.2015.11.005.

Tintino, S. R., Oliveira-Tintino, C. D. M., Campina, F. F., Costa, M. S., Cruz, R. P., Pereira R. L. S., ... Balbino, V. Q. (2017). Cholesterol and ergosterol affect the activity of Staphylococcus aureus antibiotic efflux pumps. Microbial Pathogenesis, 104, 133-136. https://doi.org/10.1016/j.micpath.2017.01.019.

Tomšik, A., Pavlić, B., Vladić, J., Ramić, M., Brindza, J., \& Vidović, S. (2016) Optimization of ultrasound-assisted extraction of bioactive compounds from wild garlic (Allium ursinum L.). Ultrasonics Sonochemistry, 29, 502-511.

Vieira, V., Prieto, M. A., Barros, L., Coutinho, J. A. P., Ferreira, O., \& Ferreira, I. C. F. R. (2017). Optimization and comparison of maceration and microwave extraction systems for the production of phenolic compounds from Juglans regia L. for the valorization of walnut leaves. Industrial Crops and Products, 107, 341-352.

Wang, W., Jung, J., Tomasino, E., \& Zhao, Y. (2016). Optimization of solvent and ultrasound-assisted extraction for different anthocyanin rich fruit and their effects on anthocyanin compositions. LWT - Food Science and Technology, 72, 229-238.

Wang, X., Wu, Y., Chen, G., Yue, W., Liang, Q., \& Wu, Q. (2013). Optimisation of ultrasound assisted extraction of phenolic compounds from Sparganii rhizoma with response surface methodology. Ultrasonics Sonochemistry, 20(3), 846-854.

Zhai, F. H., Wang, Q., \& Han, J. R. (2015). Nutritional components and antioxidant properties of seven kinds of cereals fermented by the basidiomycete Agaricus blazei. Journal of Cereal Science, 65, 202-208. https://doi.org/10.1016/j.jcs.2015.07.010.

Zhu, Z., He, J., Liu, G., Barba, F. J., Koubaa, M., Ding, L., ... Vorobiev, E. (2016). Recent insights for the green recovery of inulin from plant food materials using non-conventional extraction technologies: A review. Innovative Food Science and Emerging Technologies, 33, 1-9. 